\title{
Depletion of the cisplatin targeted HMGB-box factor UBF selectively induces p53-independent apoptotic death in transformed cells
}

\author{
Nourdine Hamdane ${ }^{1,2,3}$, Chelsea Herdman ${ }^{1,2}$, Jean-Clement Mars ${ }^{1,2}$, Victor \\ Stefanovsky ${ }^{1}$, Michel G. Tremblay ${ }^{1}$, Tom Moss ${ }^{1,2}$ \\ 1'Laboratory of Growth and Development, St-Patrick Research Group in Basic Oncology, Cancer Division of the Quebec \\ University Hospital Research Centre, Québec, QC, Canada \\ ${ }^{2}$ Department of Molecular Biology, Medical Biochemistry and Pathology, Faculty of Medicine, Laval University, Québec, QC, \\ Canada \\ ${ }^{3}$ Present address: Inserm, U1110, Institute of Viral and Liver Diseases, Strasbourg, France
}

Correspondence to:

Tom Moss, e-mail: Tom.Moss@crhdq.ulaval.ca

Keywords: Upstream binding factor (UBF/UBTF), ribosome biogenesis, oncogenic stress, apoptosis, cisplatin

Received: January 23, $2015 \quad$ Accepted: July 27, $2015 \quad$ Published: August 07, 2015

\section{ABSTRACT}

\begin{abstract}
Cisplatin-DNA adducts act as strong decoys for the Upstream Binding Factor UBF (UBTF) and have been shown to inhibit transcription of the ribosomal RNA genes by RNA polymerase $I$. However, it is unclear if this plays a significant role in the chemotherapeutic activity of cis- or carboplatin. We find that cisplatin in fact induces a very rapid displacement of UBF from the ribosomal RNA genes and strong inhibition of ribosomal RNA synthesis, consistent with this being an important factor in its cytotoxicity. Using conditional gene deletion, we recently showed that UBF is an essential factor for transcription of the ribosomal RNA genes and for ribosome biogenesis. We now show that loss of UBF arrests cell proliferation and induces fully penetrant, rapid and synchronous apoptosis, as well as nuclear disruption and cell death, specifically in cells subjected to oncogenic stress. Apoptosis is not affected by homozygous deletion of the $p 53$ gene and occurs equally in cells transformed by SV40 T antigens, by Myc or by a combination of Ras \& Myc oncogenes. The data strongly argue that inhibition of UBF function is a major factor in the cytotoxicity of cisplatin. Hence, drug targeting of UBF may be a preferable approach to the use of the highly toxic platins in cancer therapy.
\end{abstract}

\section{INTRODUCTION}

The commonly used chemotherapeutic drugs cisplatin and carboplatin are generally considered to exert their cytotoxicity by inducing DNA damage. These drugs interact with DNA to form intra- and interstrand crosslinks, which must be repaired for the cell to proliferate [1]. Hence, cells that grow more rapidly or are limited in their capacity to repair DNA should disproportionately suffer cell death, which often occurs by apoptosis. Consequently, growth factor driven tumour growth and deficits in the ability to rapidly repair DNA both enhance the ability of cisplatin to induce cell death [1-5]. DNA-platin adducts are also aberrantly bound by a range of nuclear proteins, and this in general enhances cell death by delaying their repair [6, 7]. Important among these nuclear proteins are members of the High Mobility A and B families (HMGA and HMGB), which display elevated affinities for the bent DNA structure of the platin adducts via their HMGA-box and HMGB-box DNA binding domains [8-10]. Upstream Binding Factor (UBF) is an abundant multi-HMGB-box transcription factor that defines the active state of ribosomal RNA (rRNA) gene chromatin by replacing the core histones and is essential for transcription of these genes [11-13]. It has long been known that UBF has a particularly high affinity for cisplatin-DNA adducts, which may act as molecular decoys to attract this factor away from the rRNA genes 
and in so doing suppress their transcription [14-19]. Since transcription of the rRNA genes is the central event in the assembly of ribosomes, the protein factories of the cell, their activity is essential for cell growth and proliferation. The ability of cisplatin adducts to act as decoys for UBF binding could, therefore, enhance the drugs cytotoxicity either by inhibiting DNA repair, by inhibiting ribosome assembly, or both.

The rRNA genes are transcribed by RNA polymerase I (RPI/PolI), which is dedicated to this task. UBF is an HMGB-box DNA binding protein and one of the two essential RPI basal transcription factors [11, 20-23]. UBF is generally thought to mediate binding of the preinitiation factor SL1/TIF1B and pre-initiation complex (PIC) assembly at the rRNA gene promoter. But UBF also forms a nucleosome-like structure that replaces histone chromatin throughout the transcribed regions of the rRNA genes and is able to regulate RPI transcription elongation in response to growth factor signalling [11, 24-28].

Ribosomal biogenesis is the process by which ribosomal RNA (rRNA) is transcribed, processed and assembled with the ribosomal proteins to create ribosomes $[21,29]$. This energy consuming process is accomplished in the nucleolus and requires the action of the three RNA polymerases along with more than 200 different proteins and several hundred snoRNP complexes. Regulation of ribosome synthesis constitutes a major determinant of the increased protein synthesis needed for cell proliferation and, as such, its up-regulation occurs in many cancers $[30,31]$. An increased nucleolar volume reflects this increased ribosome synthesis, and is therefore a biomarker of cancer that was recognized already 80 years ago [32-34]. In fact, rRNA transcription is a common and probably an essential target of many oncogenes (Myc $[35,36]$, SV40-T antigen $[37,38]$ and the Ras and mTOR signalling pathways [39-43]), and tumour suppressors (p53 [44], ARF [45-47], Rb [48, 49] and PTEN [50]).

Ribosomal biogenesis is such a central process in cell growth that it is also under the direct surveillance of the p53 pathway [51]. Defects in rRNA gene transcription [52], rRNA processing [53] or ribosome assembly [54] all cause p53 stabilization and arrest of cell proliferation. These findings have led to the investigation of small molecule inhibitors of ribosomal transcription as potential chemotherapeutic agents. Inhibition of the RPI preinitiation factor SL1/TIF1B [55] or induced proteasome degradation of the RPI large subunit [56] both lead to arrest of rRNA synthesis and mediate cell death dependent on p53 function. However, the key to successful cancer therapy remains the selective targeting of cancer cells, and since p53 is often inactivated in human cancers, therapies that depend on functional p53 have limited application. Our data now suggest that inhibition the RPI basal transcription factor UBF (Upstream Binding Factor) represents a particularly valuable p53-independent target for cancer therapy.
Here we show that displacement of UBF and ablation of rRNA synthesis are very early effects of cisplatin treatment, and that in the absence of cisplatin, elimination of UBF protein is sufficient to induce fully penetrant apoptotic cell death. Using cell cultures conditional for UBF expression, we find that complete loss of ribosome biogenesis induces synchronous and fully penetrant, p53-independent cell death by apoptosis specifically in cells transformed by known oncogenes. The data argue that a major factor in the cytotoxicity of cisplatin and similar drugs is their ability to inhibit the function of UBF. This suggests that UBF itself represents a preferred target for anticancer drug development.

\section{RESULTS}

Previous data has clearly indicated that cisplatin treatment of human cells leads to a partial or full displacement of human UBF and inhibition of rRNA synthesis $[14,15,17,18]$. However, to what extent this plays a role in the selective cytotoxicity of cisplatin is not known. When the Mouse Embryonic Fibroblast (MEF) derived cell line NIH3T3 was treated for $4 \mathrm{~h}$ with $30 \mu \mathrm{M}$ cisplatin, a concentration calculated to be equivalent to the dose commonly used in therapy (e.g see $[57,58]$ ), a large proportion of endogenous UBF was displaced from nucleoli and scattered throughout the nucleus at a large number of foci (Figure S1). These foci were devoid of the other nucleolar proteins fibrillarin and RPI (data not shown), which remained together in dense nuclear bodies somewhat similar to the nucleolar precursor bodies forming on conditional deletion of the Ubf gene [11].

\section{Cisplatin displaces UBF from the mouse rRNA genes and arrests their transcription}

To better understand the effect of cisplatin, we repeated and extended these studies using the independently isolated, iMEF cell line $\left(U b f^{w t / w t} / \mathrm{Er}^{-} \mathrm{Cr} \mathrm{e}^{+/+} /\right.$ $S v T)$ previously characterized by Hamdane et al. [11]. Already after $4 \mathrm{~h}$ exposure of these cells to $30 \mathrm{uM}$ cisplatin, UBF was seen to coalesce from its normal specular distribution within nucleoli into more intense foci, while fibrillarin showed some degree of coalescence but was less affected (Figure 1). When these cells were cultured for a further $\sim 18 \mathrm{~h}$ in the absence of cisplatin, the UBF foci became more intense and UBF, but not fibrillarin, formed foci throughout the nucleus. The timing of the changes in UBF delocalization corresponded closely with changes in the interaction of UBF with the rRNA genes and with the transcription of these genes (Figure 2). After $4 \mathrm{~h}$ of cisplatin treatment a mean reduction in UBF binding of $80 \%$ was observed across the $47 \mathrm{~S}$ precursor rRNA coding region, and this corresponded with an $80 \%$ reduction in rRNA synthesis (Figure $2 \mathrm{~B}$ and $2 \mathrm{C}$ ). (Due to its $5^{\prime}$ position in the $47 \mathrm{~S}$ precursor, $18 \mathrm{~S}$ rRNA synthesis was slightly less 

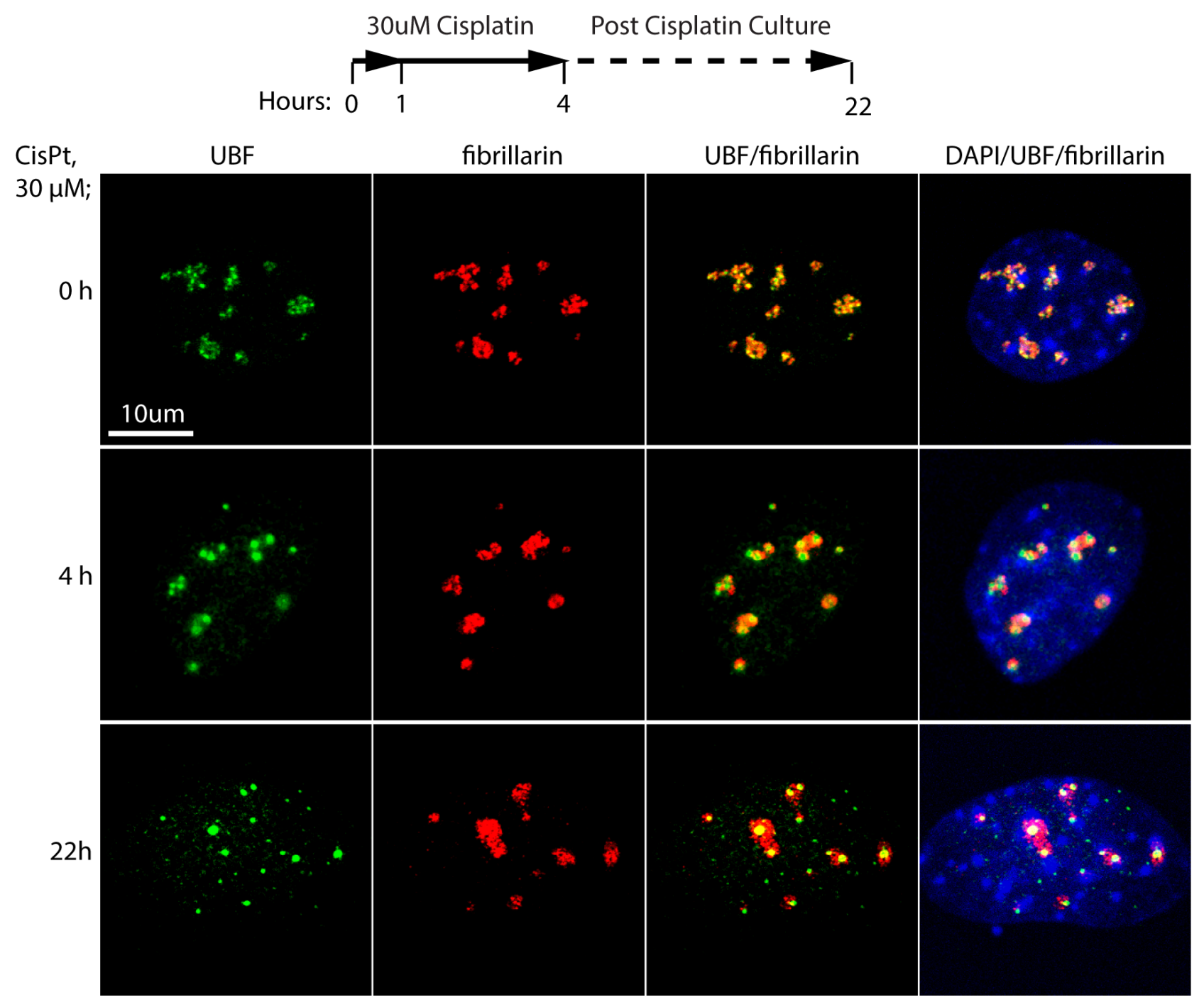

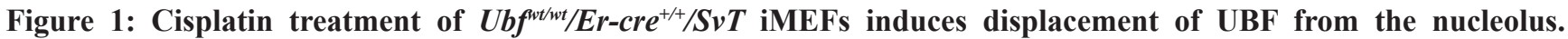
iMEFs were treated with $30 \mu \mathrm{M}$ cisplatin for $4 \mathrm{~h}$ in full medium or left untreated (0), then either fixed immediately or cultured in fresh medium lacking cisplatin overnight $(22 \mathrm{~h})$ as indicated in the timeline before fixing. The fixed samples were then subjected to indirect immunofluorescence analysis of UBF (green), fibrillarin (red) and DNA stained with DAPI (blue).

affected at $4 \mathrm{~h}$ than the 28S rRNA, but nevertheless was reduced by over $60 \%$ after $4 \mathrm{~h}$ cisplatin exposure, data not shown). $22 \mathrm{~h}$ after cisplatin exposure rRNA synthesis was no longer detectable. The effects of cisplatin on the activity of the rRNA genes also corresponded to an arrest of cell proliferation, no increase in the viable cells count being detected after the $4 \mathrm{~h}$ cisplatin treatment, and to a subsequent loss of viability (Figure 2D). These data suggest that the timeline of cisplatin cytotoxicity is consistent with its effects being mediated at least in part by disruption of UBF function, and the arrest of rRNA gene transcription and, hence, of ribosome biogenesis. Since cisplatin is a key chemotherapeutic agent that acts by inducing apoptotic cell death somewhat selectively in transformed cells (e.g. [3]), we sought to determine whether or not this activity could also be explained by the inhibition of UBF function.

\section{UBF loss disrupts nucleolar functions in both primary and transformed MEFs}

We previously generated mice conditional for the Ubf gene and demonstrated that loss of this gene arrested mouse development at the morula stage [11]. SV40Tt immortalized Mouse Embryonic Fibroblasts or iMEFs $\left(U b f^{f l f t} / E r-\mathrm{Cre}^{+/+} / \mathrm{SvT}\right)$ generated from these mice allowed us to show that UBF was essential for transcription of the rRNA genes and for the existence of a functional nucleolus [11]. Not surprisingly, despite their limited proliferation potential, primary MEFs derived from these mice also require UBF for rRNA synthesis and for the maintenance of nucleoli (Figure S2). Thus, UBF loss in primary MEFs recapitulated the effects observed in the transformed iMEFs. 
A)

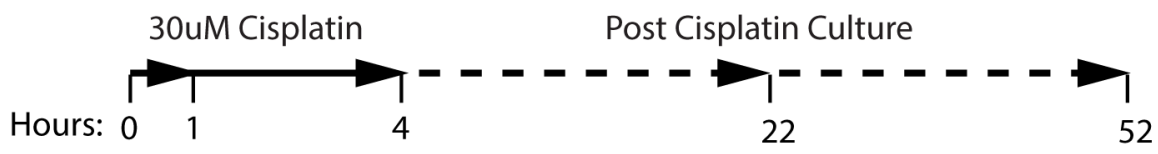

B)

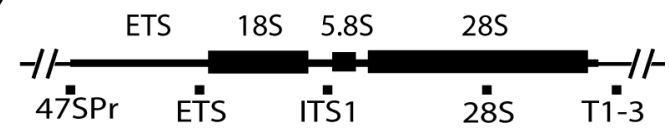

C) 30uM Cisplatin

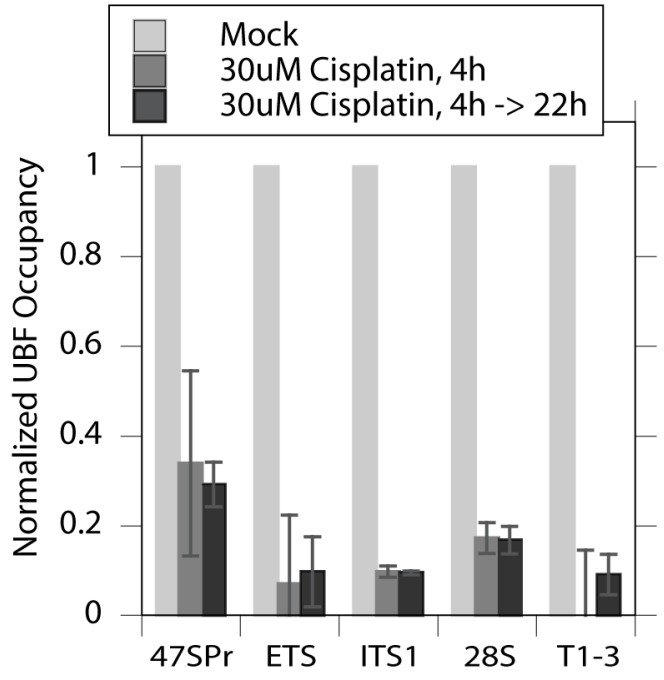

D)
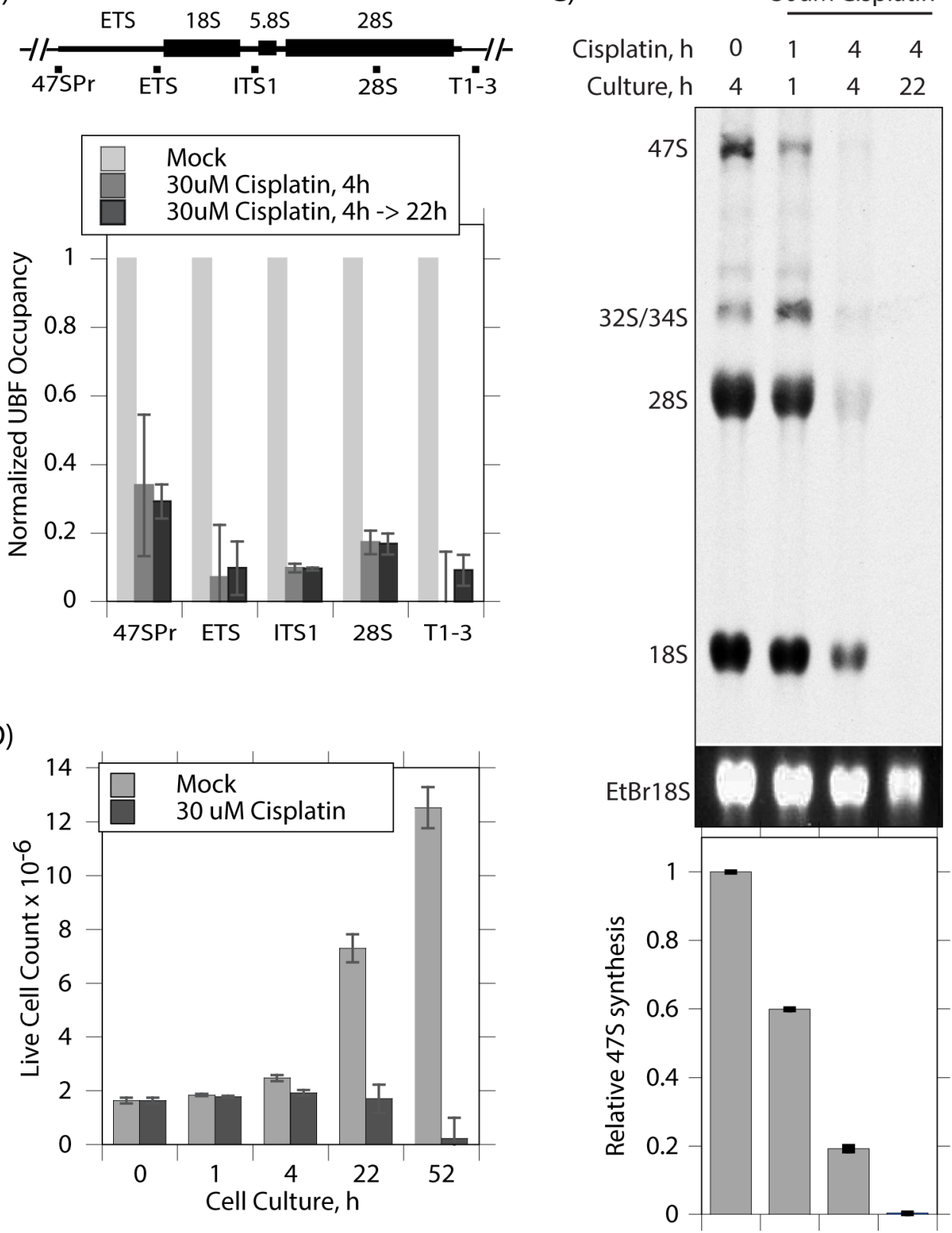

Figure 2: Cisplatin coordinately displaces UBF from the rRNA genes and arrests their transcription. A. Timeline of cisplatin treatment and culture of $U b f^{\text {wtw } w / E r-c r e} e^{+/} / S v T$ iMEFs. B. ChIP analyses of UBF occupancy across the rRNA gene $47 \mathrm{~S}$ transcribed region. The positions of amplicons is indicated above the histogram showing the UBF occupancy normalized to that in the mock treated cells. C. Synthesis rate of rRNA determined by $\left[{ }^{3} \mathrm{H}\right]$-uridine metabolic labelling of mock treated cells and at the indicated times post cisplatin treatment. The upper panel displays a fluorogram of $\left[{ }^{3} \mathrm{H}\right]-\mathrm{rRNA}$, the central panel the corresponding EtBr stained total $18 \mathrm{~S}$ rRNA, and the lower panel quantitation of $\left.{ }^{3} \mathrm{H}\right]$ incorporation into $47 \mathrm{~S}$ rRNA performed in triplicate. D. Live cell counts at indicated times following cisplatin treatment performed in triplicate. 


\section{Transformed iMEFs, but not primary MEFs, undergo synchronous apoptosis following $\boldsymbol{U b f}$ inactivation}

Despite the apparently identical responses of the primary MEFs and the iMEFs to UBF loss, it became obvious from observing these cultures that the two cell types behaved very differently macroscopically. Inactivation of rRNA gene transcription in the Ubf flffl $\mathrm{Er}_{-\mathrm{Cre}} \mathrm{C}^{++} / \mathrm{SvT}$ iMEFs induced changes in cell morphology soon after complete UBF depletion and the shutdown of rRNA synthesis. iMEFs became highly elongated and this presaged cell death as determined by plasma membrane failure (trypan blue), mitochondrial membrane depolarization (MitoTracker) and loss of clonal viability (Figure S3A to S3D). Control $U b f^{w t w t} / E r-\mathrm{Cre}^{+/+} / \mathrm{Sv} T$ iMEFs suffered none of these effects, clearly demonstrating that cell death was exclusively the result of inactivation of the $U b f$ gene. Interestingly, we detected no selective reduction of total cellular RNA in the $U b f^{f l f l} / E r-\mathrm{Cre}^{+/+} / S v T$ iMEFs relative to their wild type counterparts during UBF depletion that might suggest a role of ribosome depletion in the selective induction of apoptosis (data not shown). In contrast to the behavior of the $U b f^{f l l f l} / E r-\mathrm{Cre}^{+/+} / S v T$ iMEFs, the primary $U b^{f l l f l} / E r-c r e^{+/+}$MEFs showed no evidence of major morphological changes and survived in culture for many days following complete UBF loss, maintaining plasma membrane integrity and mitochondrial function (Figure S3A to S3C).

To better understand the different responses of the transformed iMEFs and primary MEFs to UBF loss, we analyzed them for typical markers of cell death. TUNEL (terminal deoxynucleotidyl transferase-mediated dUTP nick end-labeling) analysis detects the single strand DNA cleavage that is characteristic of the early stages of apoptotic cell death. $U b f^{f l f l} / E r-\mathrm{Cre}^{+/+} / \mathrm{SvT}$ iMEFs became TUNEL positive at $96 \mathrm{~h}$ pHT, just $24 \mathrm{~h}$ after complete shutdown of rRNA synthesis, while the control $U b f^{\text {wt wt } / \text { / }}$ $\mathrm{Er}_{-\mathrm{Cre}}{ }^{++} / \mathrm{SvT}$ iMEFs remained TUNEL-negative throughout (Figure 3A). The TUNEL signal was fully penetrant and occurred synchronously, Ubf $f^{f l f l} / E r-\mathrm{cre}^{+/+} / S v T$ iMEFs being TUNEL-negative at $72 \mathrm{~h}$ pHT but all becoming TUNEL-positive at $96 \mathrm{~h}$ pHT. In contrast, the Ubfflffl $\mathrm{Er}-\mathrm{cre}^{+/+}$primary MEFs remained TUNEL-negative at least until $144 \mathrm{~h}$ pHT, (Figure 3B and data not shown).

Concomitant with the onset of TUNEL-positive apoptosis, the $U b^{f l l f l} / E r-c r e^{+/+} / S v T$ iMEFs were also found to activate Caspase 3 from $96 \mathrm{~h} \mathrm{pHT}$, as determined by the release of the $17 \mathrm{kD}$ peptide (p17) cleavage product (Figure 4A). In contrast, the control $\mathrm{Ubf}^{\mathrm{wt} t w t} / \mathrm{Er}-\mathrm{Cre}^{+/+} / \mathrm{SvT}$ iMEFs displayed no significant cleavage of Caspase 3, consistent with the lack of a TUNEL signal. Further, Caspase 3 was not significantly activated in the primary MEFs (Figure 4B). Though a certain level of cleavage was detected in both $U b f^{f l f l}$ and $U b f^{\text {wt } / w t}$ MEFs, this was much weaker than observed in the $U b f^{f l f l} / E r-\mathrm{Cre}^{+/+} / S v T$ iMEFs as can be seen by comparison with Staurosporin-treated iMEFs.

Interestingly, unlike the deletion of UBF, deletion of the essential RPI initiation factor TIF1A/Rrn3 did not induce apoptosis in SV40Tt transformed MEFs. 4-HT treatment of $T I F 1 A^{f / f /} / E r-c r e^{+/+} / S v T$ :MEFs resulted in complete depletion of TIF1A by $48 \mathrm{~h}$ pHT, as observed for UBF, but did not lead to activation of Caspase 3 , nor to a TUNEL signal (Figure S4A and S4B). Thus, the induction of apoptosis in the SV40Tt transformed cells was not a general property of the arrest of rRNA gene transcription, suggesting it is specific to UBF depletion.

Given that the iMEFs were initially immortalized by the SV40 Tt oncogene $(S v-T)$, known to inactivate p53 $[59,60]$, it was not surprising to find the p53 levels in these cells were constitutively elevated and were not further induced by inactivation of the $U b f$ gene or by treatment with Staurosporin (Figure 4A). Thus, it was unclear whether or not $\mathrm{p} 53$ played a role in the apoptotic response in these cells. This question is directly addressed below using homozygous inactivation of the p53 gene. However, it should be noted that inactivation of the $U b f$ gene in the primary MEFs did not enhance the levels of p53 protein, which remained extremely low throughout (Figure 4B).

\section{Apoptosis is accompanied by the generation of a "nucleosomal ladder" of DNA cleavage}

Apoptosis is often accompanied by internucleosomal cleavage of genomic DNA to generate a "nucleosomal ladder" [61, 62], due to the result of the release of the nuclease EndoG from mitochondria $[63,64]$. Beginning at or before $120 \mathrm{~h} \mathrm{pHT}$ we observed this characteristic nucleosomal fragmentation of genomic DNA in the apoptotic Ubf fllfl/Er-Cre $e^{+/+} / S v T$ but not in the control $U b f^{w t w t} / E r-c r e^{+/+} / S v T$ iMEFs (Figure 4C), nor in the corresponding primary MEFs (data not shown). Thus, three distinct markers; TUNEL signal, Caspase 3 cleavage and a nucleosomal ladder, indicated that on UBF loss MEFs underwent classic apoptotic cell death after oncogenic transformation with SV40-T, while UBF loss in untransformed MEFs induced none of these markers.

\section{UBF loss blocks proliferation and DNA replication, causing cell cycle arrest}

To better understand the mechanisms leading to apoptosis in the transformed iMEFs, we determined the effects of $U b f$ inactivation on cell cycle progression and cell division. Before tamoxifen treatment, the Ubf flfl/ $E r-\mathrm{Cre}^{+/+} / \mathrm{SvT}$ iMEFs displayed a large ( $\left.\sim 50 \%\right)$ actively replicating S-phase population (Figure 5A). Their proliferation was near completely arrested by $48 \mathrm{pHT}$, corresponding with the elimination of UBF protein and with the near complete shutdown of rRNA synthesis 
A)

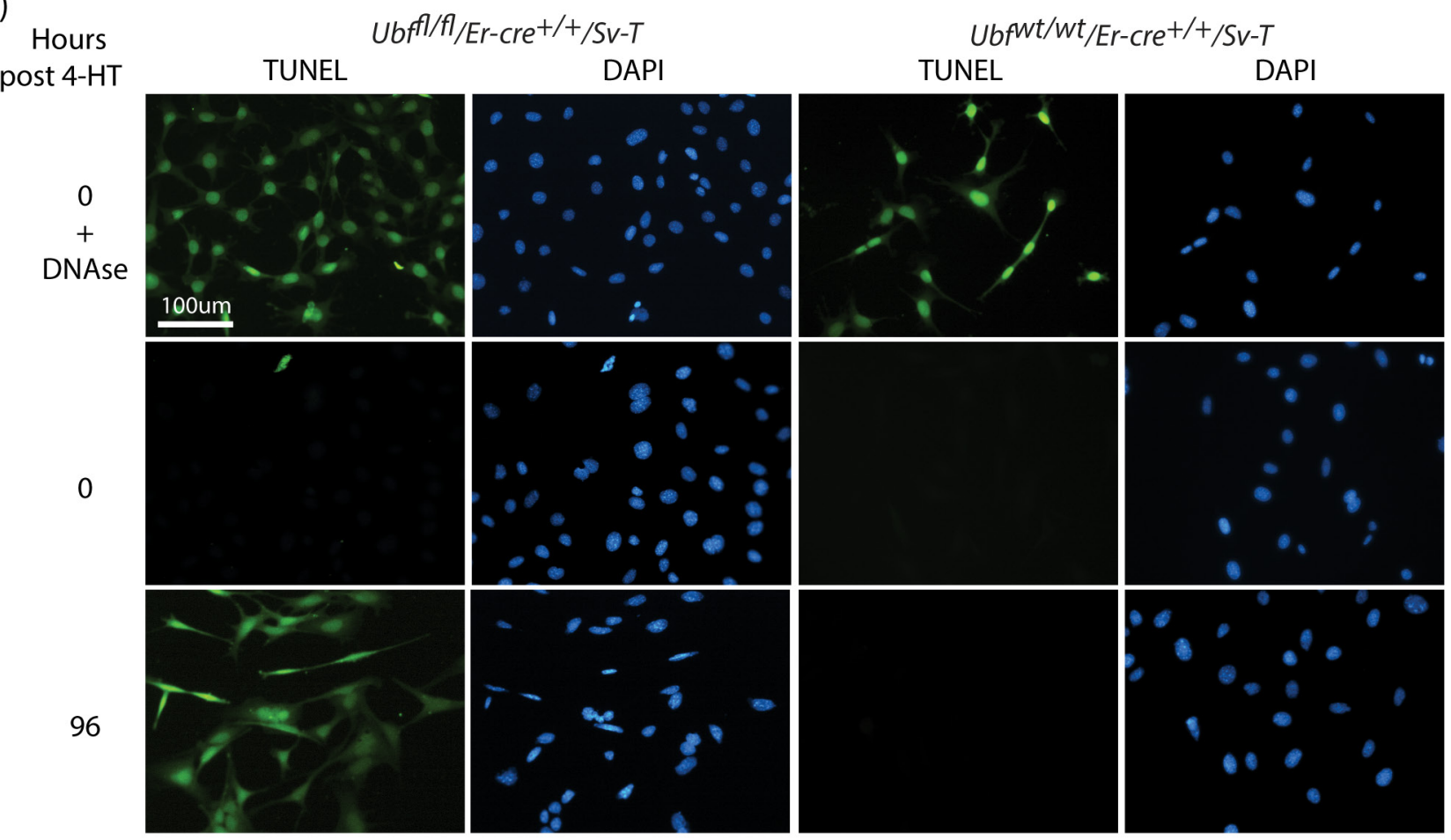

B)

Hours post 4-HT Ubfl/fl/Er-cret/+

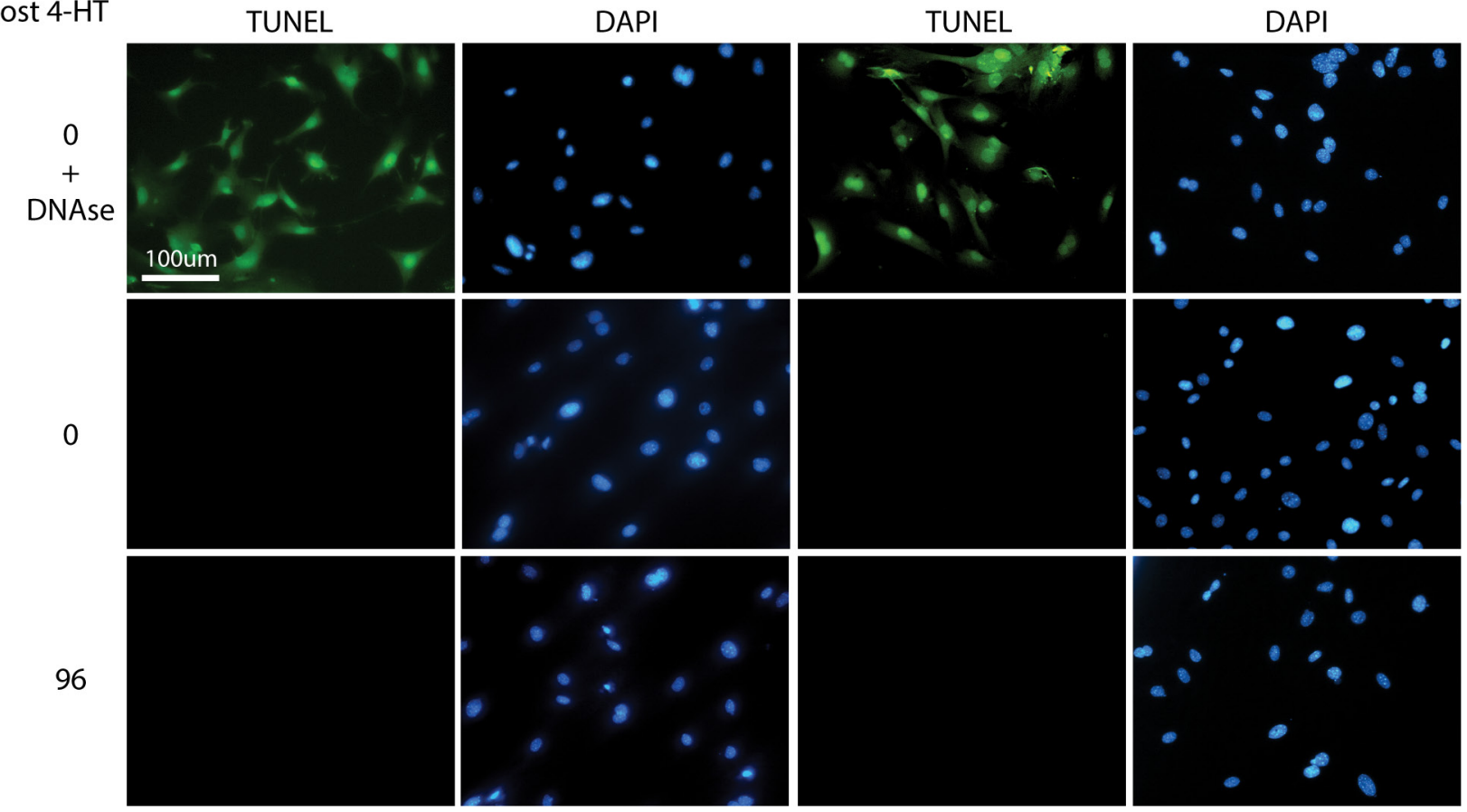
Ubfwt/wt/Er-cre+/+

Figure 3: UBF loss induces synchronous apoptotic cell death selectively in oncogenically transformed iMEFs.

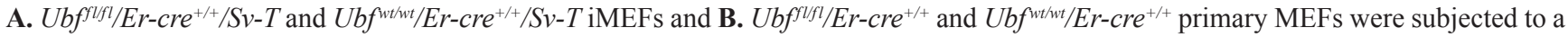
TUNEL reaction immediately before, and at several time points after, treatment with 4-HT. In both cases, recombination and UBF protein levels were assayed in parallel and closely followed those shown in Figure S2B and S2C. 


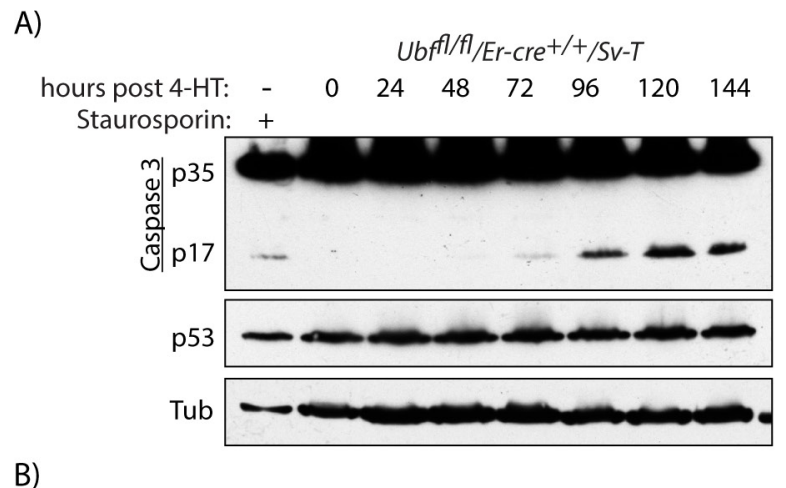
\begin{tabular}{llllllll} 
B) & \multicolumn{1}{c}{ Ubfl/fl/Er-cret/+ } \\
hours post 4-HT: - & 0 & 24 & 48 & 72 & 96 & 120 & 144 \\
iMEF+Staurosporin: + & & & & & & &
\end{tabular}
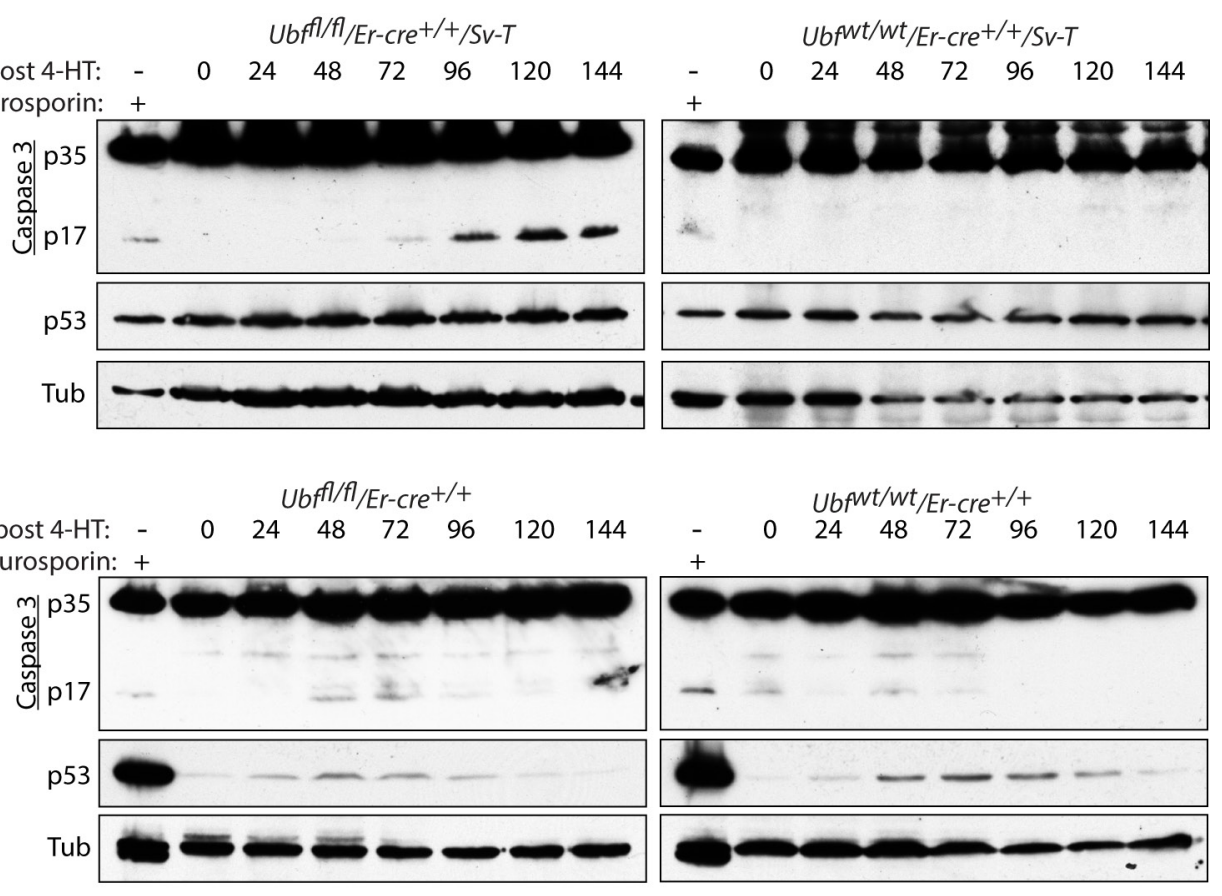

C)

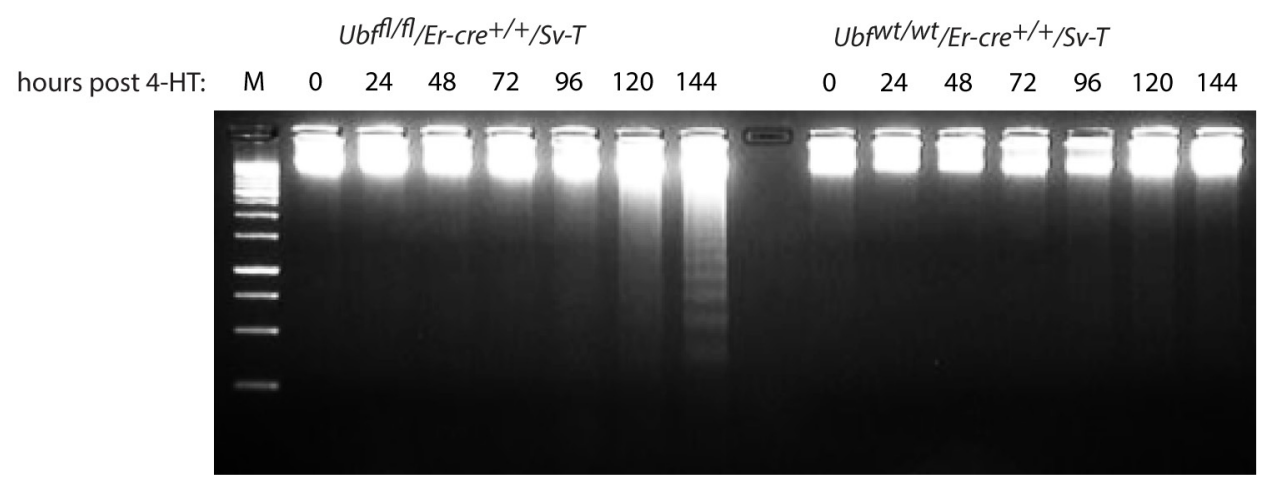

Figure 4: UBF loss induces selective Caspase 3 cleavage in transformed iMEFs cells. A. Ubf $f^{f l f l} / E r-c r e^{+/+} / S v-T$ and $U b f^{w t / w t} /$

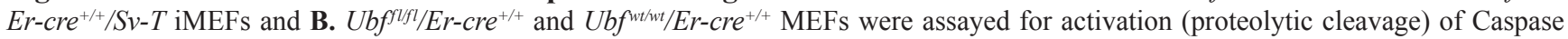
3 immediately before and at time points after treatment with 4-HT. In B) "iMEF+Staurosporin" refers to the extract from iMEFs cells treated with $1 \mu \mathrm{M}$ Staurosporin used in A, and allows a direct comparison of p17 and p53 levels in iMEFs with those in primary MEFs. C. Electrophoretic fractionation on $1.5 \%$ agarose of genomic DNA recovered from $U b f^{f l l f l} / E r-c r e^{+/+} / S v-T$ and $U b f^{v t / w t} / E r-c r e^{+/+} / S v-T$ iMEFs at different times post tamoxifen treatment (pHT). In A) to C), recombination and UBF protein levels were assayed in parallel with each analysis and closely followed those shown in Figure S2B and S2C.

(e.g. see Figure S2C to S2E and [11]). By $72 \mathrm{~h}$ pHT, iMEFs had also stopped active DNA replication and the G2 population abruptly increased at the expense of S-phase cells, while the fraction of G1/G0 cells remained constant (Figure 5A and S5A). Concomitantly, the mitotic index fell to zero as determined by the fraction of cells phosphorylated on serine 28 of histone H3 (H3-S28P) (Figure 5C and 5D and Figure S5B). Together these data suggested that many apparently G2 iMEFs were unable to complete their passage through mitosis. Parallel analysis of $U b f^{\text {fut } / w t} / \mathrm{Er}_{\mathrm{Cr}} \mathrm{Cre}^{++} / \mathrm{SvT}$ iMEFs post tamoxifen treatment revealed none of these effects, DNA replication and cell proliferation continuing essentially unabated (Figure 5A, $5 \mathrm{C} \& 5 \mathrm{D}$ and $\mathrm{S} 5 \mathrm{~B})$.
The situation was somewhat different in the primary $U b_{f f l f l} / E r-\mathrm{Cre}^{+/+}$and control $U f^{f^{w l w t} /} / \mathrm{Er}^{-\mathrm{Cre}^{+/+}}$ MEFs (Figure 5B). These cells proliferated more slowly than iMEFs, and only a small fraction $(\sim 20 \%)$ was ever actively engaged in DNA synthesis. Further, regardless of UBF status these cells gradually arrested DNA replication between $24 \mathrm{~h}$ and $48 \mathrm{~h} \mathrm{pHT}$ and displayed a corresponding increase in G2 cells, that is up to $24 \mathrm{~h}$ earlier than for the UBF-null iMEFs. Thus, the primary MEFs underwent a natural slowing or arrest of proliferation regardless of UBF status, while proliferation arrest in the iMEFs was a direct result of the loss of UBF protein. This suggested that the catastrophic cell death observed in the iMEF cultures was related to their inability to assume a quiescent state. In 

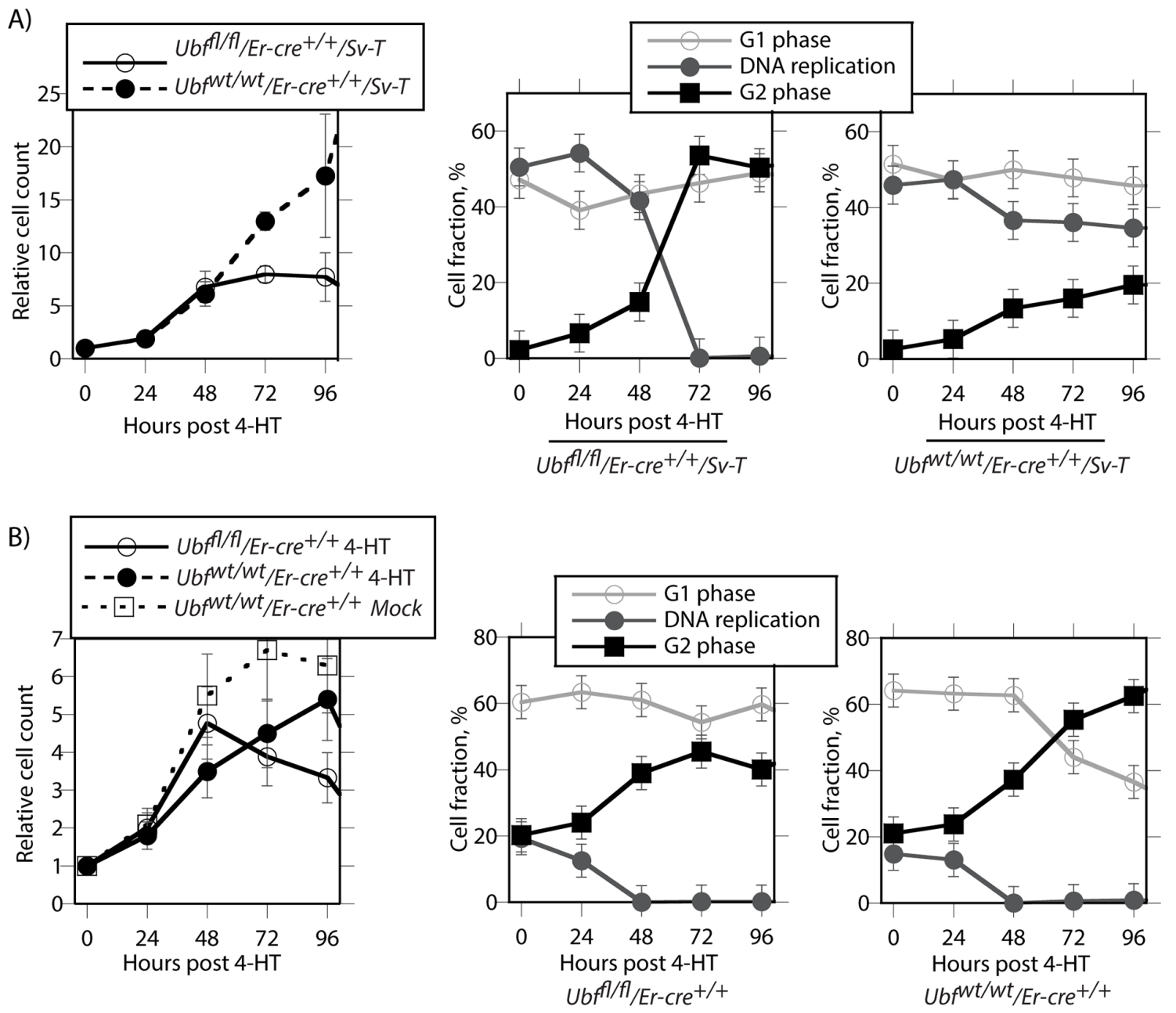

C)

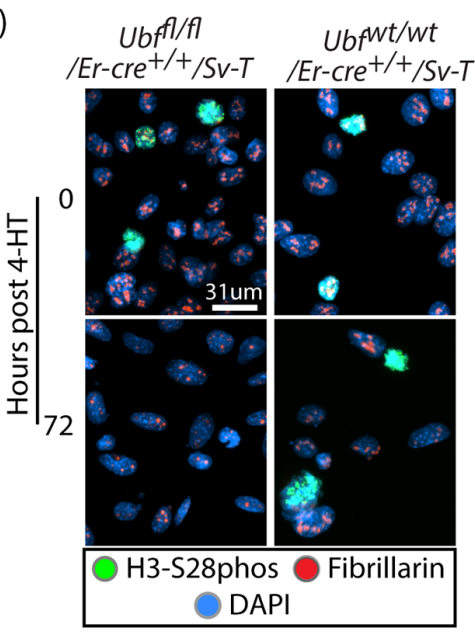

D)

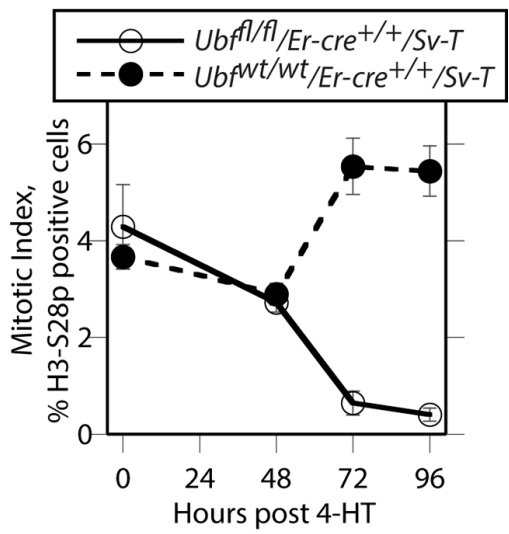

Figure 5: UBF loss arrests cell proliferation and leads to a cell cycle arrest. A. $U b f^{f l l f l} / E r-c r e^{+++} / S v-T$ and $U b f^{w w t w t} / E r-c r e^{+++} / S v-T$ iMEFs and B. the corresponding primary MEFs were analyzed for proliferation and cell cycle distribution at the indicated times post 4-HT treatment. The left-most graphics give cell counts relative to day 0 and include those for $U b f^{w / t w t} / \mathrm{Er}^{-\mathrm{cr} e^{+/+}} \mathrm{MEFs}$ cultured in the absence of 4-HT (Mock), while to the right of these are shown the cell cycle distributions obtained from FACS analyses for active DNA replication (Click-iT ${ }^{\circledR}$ EdU) and G1 and G2 DNA content (propidium iodide, PI). C. shows examples of mitotic staining, and D. a derived graphic of the mitotic index for the $U b^{f l f f l} / E r-c r e^{++/} / S v-T$ and $U b f^{w t / v t} / E r-c r e^{++/} / S v-T$ iMEFs as determined by the fraction of H3-S28phospho positive cells. In A to D, Ubf recombination and UBF protein levels were assayed in parallel and closely followed those shown in Figure S2B and S2C. 
contrast, MEFs naturally arrested proliferation and became quiescent regardless of UBF status or 4-HT treatment (Figure 5B), and hence this may have protected them from cell death on inactivation of the Ubf gene. Essentially then, UBF loss specifically targeted the SV40-Tt transformed cells for apoptotic cell death, and what is more the effect was fully penetrant. This suggests that inhibition of UBF or of ribosome biogenesis might represent an ideal target for the development of cancer specific cytotoxic drugs.

\section{Apoptosis induced by UBF loss is p53 independent}

P53 is often required for the induction of apoptosis, hence its inactivation in many cancers represents a serious limitation to the efficacy of chemo- and radiation therapies [65-67]. The SV40 Tt oncogene is known to inactivate p53 $[59,60]$, suggesting that apoptosis induced by UBF loss did not depend on functional p53. To directly evaluate the role of p53, we generated p53-null MEFs either wild type or conditional for UBF (Ubf $f^{f l f l} / E r-c r e^{+/+} / p 53^{-/-}$) (Figures 6 and S6A) and found that they were immortalized and hence could be passaged indefinitely. Despite this, they did not undergo apoptotic cell death on inactivation of the Ubf gene, and displayed neither a TUNEL signal nor Caspase 3 cleavage (Figure 6A and 6B). In contrast, after transformation with the SV40 Tt-antigens (SV40-T), the resulting p53-null (Ubfflfl/Er-cre $e^{+/+} / p 53^{-/-} / S v-T$ ) iMEFs underwent synchronous and homogeneous TUNEL positive apoptosis two days after loss of UBF, exactly as observed for the p53 positive iMEFs (Figure 6C). Thus, even in the complete absence of p53 the loss of UBF was sufficient to induce apoptosis in the SV40-Tt transformed iMEFs. However, in this case no cleavage/activation of Caspase 3 was detected (Figure 6D).

\section{p53-independent apoptosis is a general response to UBF loss in oncogene stressed cells}

It was striking that UBF loss induced fully penetrant apoptosis in SV40-Tt transformed MEFs even in the complete absence p53. To determine if this effect was specific to the SV40-Tt oncogene or occurred under other oncogenic stresses, we investigated UBF-loss in MEFs transformed by the Ras and Myc oncogenes, commonly correlated with human cancers [68]. Ubf $f^{f l f l} / E r-\mathrm{cre}^{+/+} /$ $p 53^{-/-}$MEFs were transformed by introduction of the Ras oncogene or a combination of the Ras and Myc oncogenes and the effects of inactivation of the Ubf gene were followed. In each case UBF was essentially eliminated by $48 \mathrm{~h}$ pHT (Figure S6B) and we observed a synchronous and homogeneous onset of TUNEL-positive apoptosis $48 \mathrm{~h}$ later, exactly as for SV40-Tt transformation (compare Figure 7A with $7 \mathrm{~B}$ and $7 \mathrm{C}$ ). Colony forming assays also showed that in each case cell death approached 100\% (Figure S6D). In the case of SV40-Tt and combined Ras/ Myc transformation we also observed a "nucleosomal ladder" of apoptotic DNA cleavage starting at $96 \mathrm{~h}$ pHT, that is at or just after the appearance of the TUNEL signal (Figure S6C), though this cleavage was not detected in the cells transformed with Ras alone.

\section{Oncogenic stress may induce apoptosis by aberrantly driving cells into S-phase}

When the untransformed p53-null cells (Ubfflfl) $\mathrm{Er}_{\mathrm{Cre}} \mathrm{Cr}^{+/} / \mathrm{p} 53^{-/-}$) were analyzed by FACS, we were surprised to find that, quite unlike the SV40-Tt transformed $\left(U f^{f l f f} / \mathrm{Er}-\mathrm{cre}^{+/+} / p 53^{+/+} / \mathrm{Sv}-\mathrm{T}\right)$ iMEFs (Figure 5A), UBF depletion caused a significant accumulation of cells in G1 at the expense of the actively replicating S-phase cells (Figure 8A). The G2 cell population displayed only a small increase and this anyhow closely resembled that observed for the control $U b f^{w t / w t} / E r-c r e^{+/+} / p 53^{-/-}$cells. In contrast, the $\mathrm{Sv}-\mathrm{T}$, Ras and Ras/Myc transformed Ubf flfl/Er-cre $\mathrm{CH}^{+/+} /$ $p 53^{-/}$cells displayed the same G2 phase accumulation as seen for the p53-positive iMEFs (compare Figure 8B with 5A). This suggested that transformation drives cells into and through S-phase regardless of their ability to generate a full complement of ribosomes. Such a situation would be likely to lead to gross replicative errors and hence could explain the highly penetrant apoptosis occurring in both the p53-positive and p53-null transformed MEFs, but not in the untransformed p53-null MEFs.

\section{DISCUSSION}

Our data suggest that the ability of cisplatin to cause the displacement of UBF from the nucleolus is a key mechanism by which this drug induces selective cell death, since the simple loss of UBF induces a rapid and highly penetrant apoptosis in oncogenically stressed cells. We have shown that conditional deletion of the Ubf gene induces apoptosis specifically in cells transformed by viral and cellular oncogenes. Apoptosis following UBF loss was observed not only in cells expressing SV40Tt, but also in cells expressing the oncogenes Ras and Myc. What is more, in each case apoptosis was found to be fully penetrant, all cells without exception underwent apoptotic cell death. Strikingly, the onset of apoptosis occurred synchronously in all cells two days following complete loss of UBF. Significantly, the induction of TUNELpositive cell death was completely independent of $\mathrm{p} 53$, since it occurred with the same timing and penetrance even after homozygous deletion of the p53 gene. In contrast, before oncogenic transformation primary cell cultures survived complete loss of UBF for many days after the transformed cells entered apoptosis and never underwent apoptosis.

These data strongly suggest that the commonly used chemotherapeutic drug Cisplatin, and by analogy, Carboplatin exert their cytotoxicity in large part by hijacking UBF, displacing it from the nucleolus and inhibiting ribosome biogenesis. In fact, inhibition of 
A)

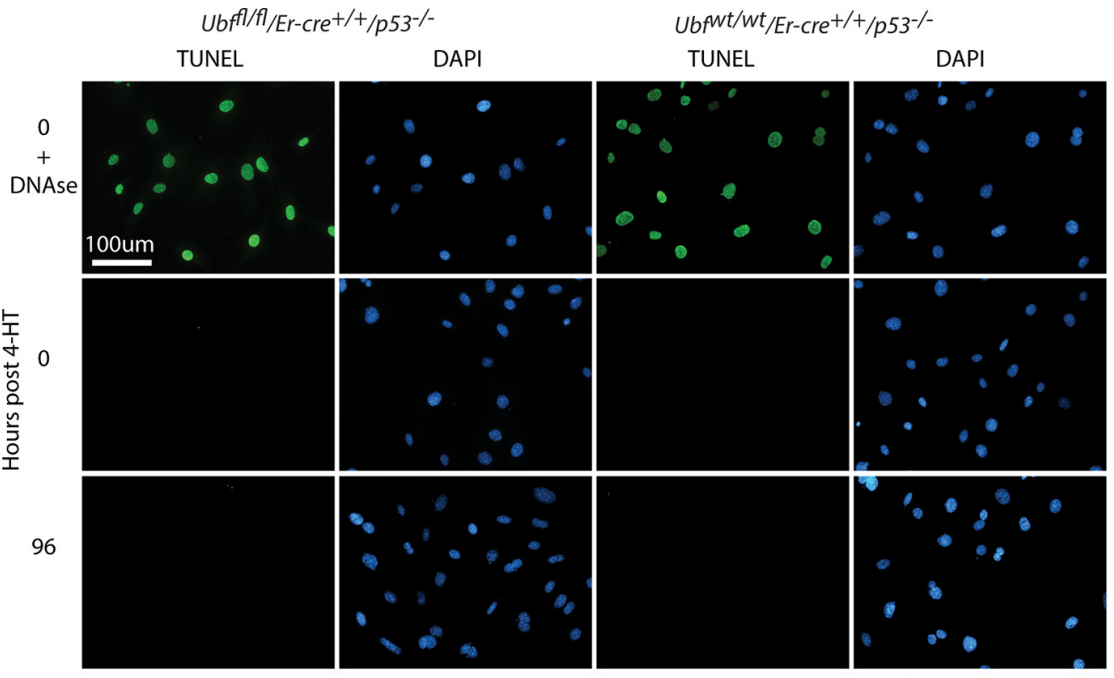

B)
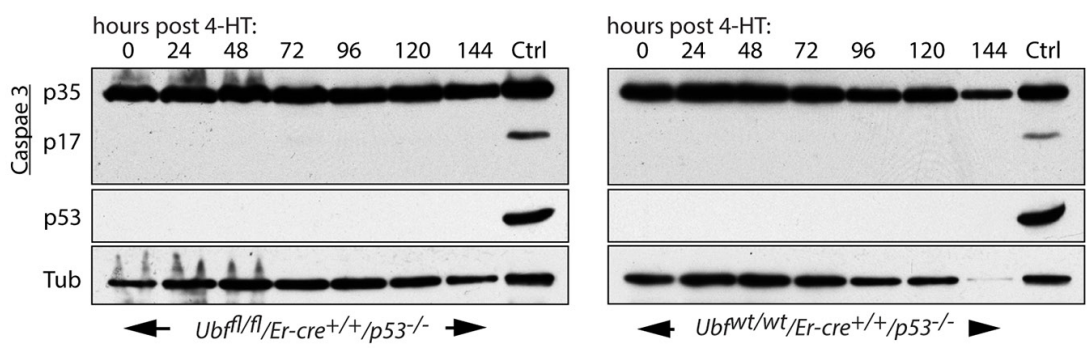

C)

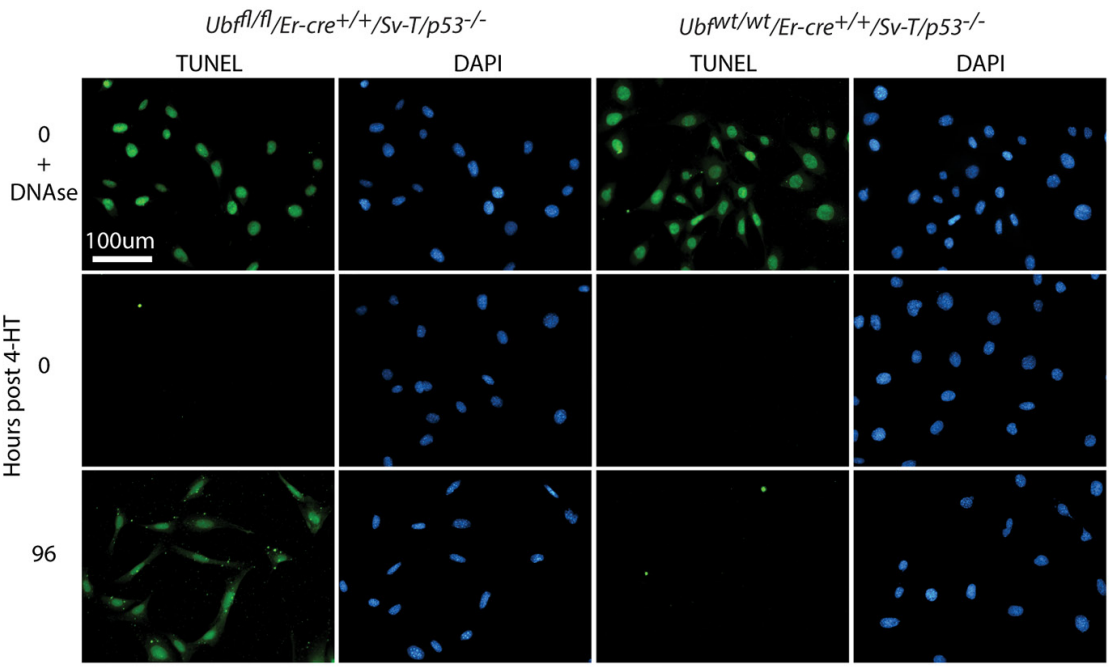

D)
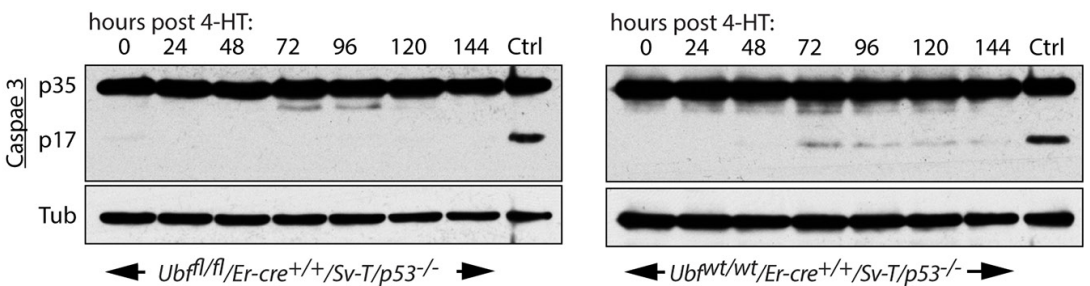

Figure 6: Apoptosis of oncogenically transformed cells after $\boldsymbol{U b f}$ gene inactivation is p53 independent. A. Ubf $f l f l / E r-c r e^{+/+} /$ $p 53^{-/-}$and $U b f^{\text {fwt } / w t} / E r-c r e^{+/+} / p 53^{-/-}$MEFs and C. $U b f^{f l f l} / E r-c r e^{+/+} / S v-T / p 53^{-/-}$and $U b f^{w t / w t} / E r-c r e^{+/+} / S v-T / p 53^{-/-}$iMEFs were subjected to a TUNEL reaction and $\mathbf{B}$. and $\mathbf{D}$. assayed for activation (proteolytic cleavage) of Caspase 3 immediately before and at several time points after treatment with 4-HT. P53-null iMEFs $\left(U f_{f l f f l} / E r-c r e^{+/+} / S v-T / p 53^{-/-}\right)$displayed the same TUNEL positive cell death, but Caspase 3 cleavage was not detected in these cells. In B) and D) "Ctrl" refers to an extract from iMEFs cells treated with $1 \mu \mathrm{M}$ Staurosporin. Recombination of the Ubf gene and UBF protein levels were assayed in parallel and closely followed those shown in Figure S2B and S2C. 
A)

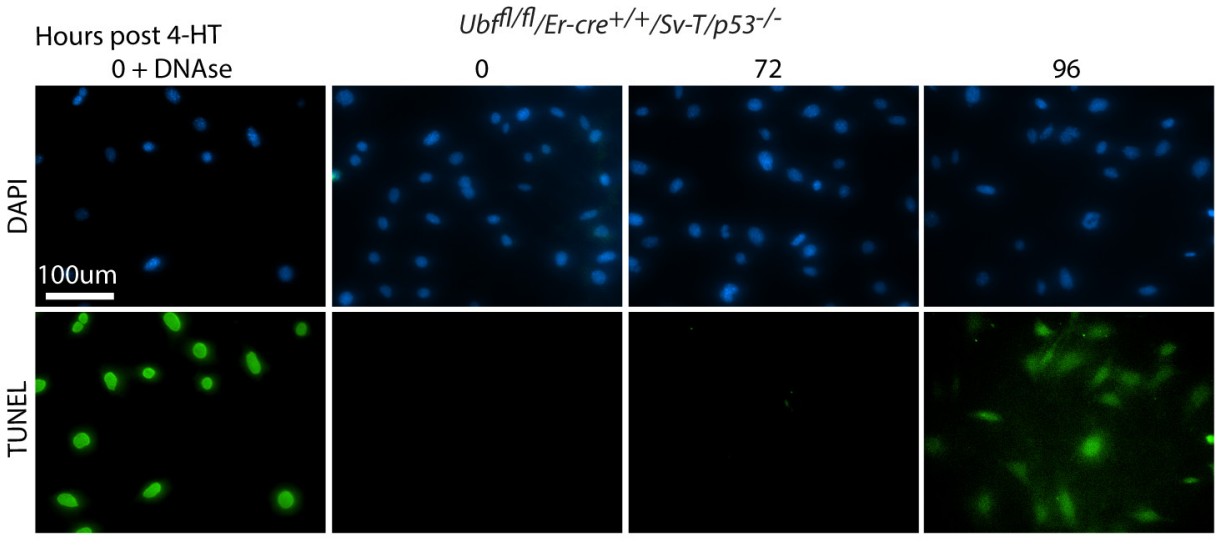

B)

Hours post 4-HT

$0+$ DNAse

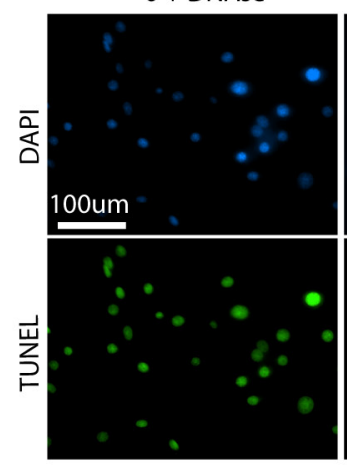

C)

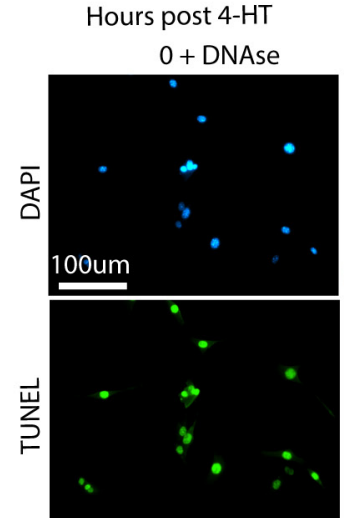

Ubfl/fl/Er-Cre ${ }^{+/+} /$Ras/p53-/-

0
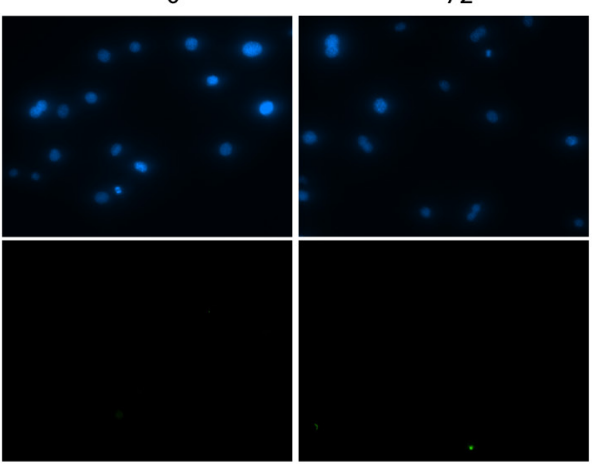

Ubfll/fl/Er-cre ${ }^{+/+} /$Ras/Myc/p53-/-

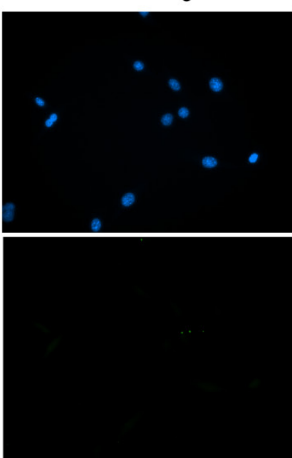

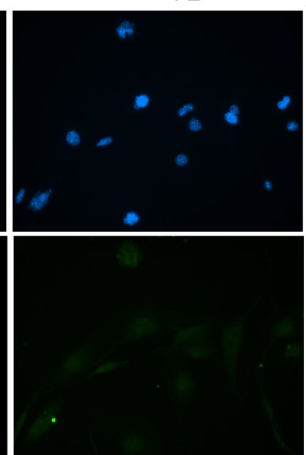

96
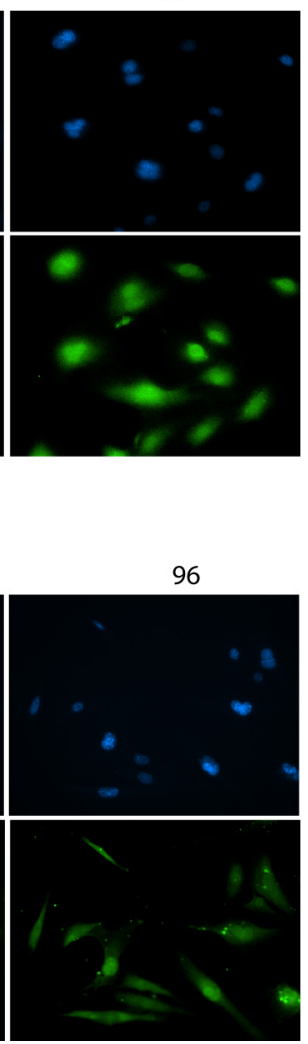

Figure 7: p53 independent apoptosis is a general response to UBF loss in an oncogenic stress context. A. $U b f^{f l l f l} / E r-c r e^{+/+} /$ $S v-T / p 53^{-/-}$and their counterpart B. Ubf $f^{f l f l} / E r-c r e^{+/+} / R a s / p 53^{-/-}$and C. $U b f^{f l f f l} / E r-c r e^{+/+} / R a s / M y c / p 53^{-/-}$iMEFs cells were subjected to a TUNEL reaction immediately before and at several time points after treatment with 4-HT. All cells synchronously became TUNEL positive at $96 \mathrm{~h}$ post 4-HT, while neither effect was observed $24 \mathrm{~h}$ previously. Recombination of the Ubf gene and UBF protein levels were assayed in parallel and closely followed those shown in Figure S2B and S2C.

ribosome biogenesis may be a more general property of the cytotoxic drugs used in chemotherapy than previously realized, including rapamycin analogs, 5-fluorouracyl and camptothecin [52, 69]. Azacytidine (Azacitidine, Vidaza) and deoxyazacytidine (Decitabine) are DNA methyltransferase inhibitors that have been shown to be active in treating myelodysplastic syndromes and acute myeloid leukemia (AML) [70-72]. The initial studies of azacytidine already showed that it strongly inhibits ribosome biogenesis, and almost certainly does so by preventing rRNA methylation [73, 74]. More recently, deoxyazacitidine was also shown to inhibit ribosome biogenesis by inhibiting rRNA processing, though the underlying mechanism of action is quite different and involves loss of rRNA gene silencing and aberrant RNA polymerase II transcription of these genes [13, 75]. 
A)

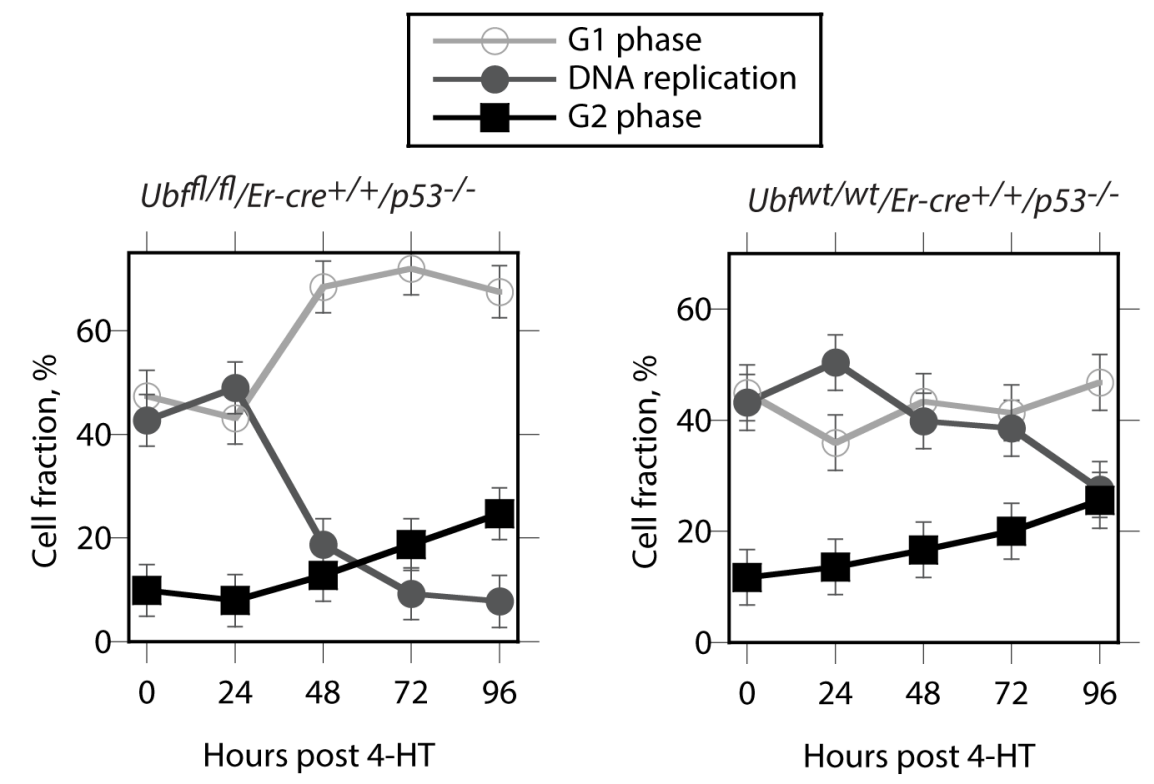

B)

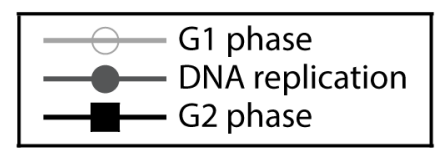

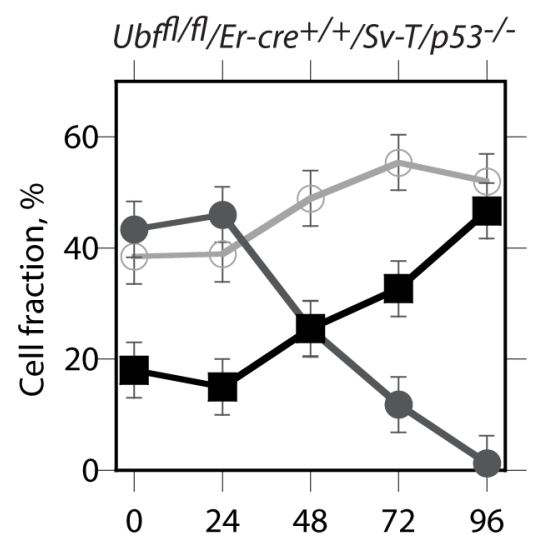

Hours post 4-HT

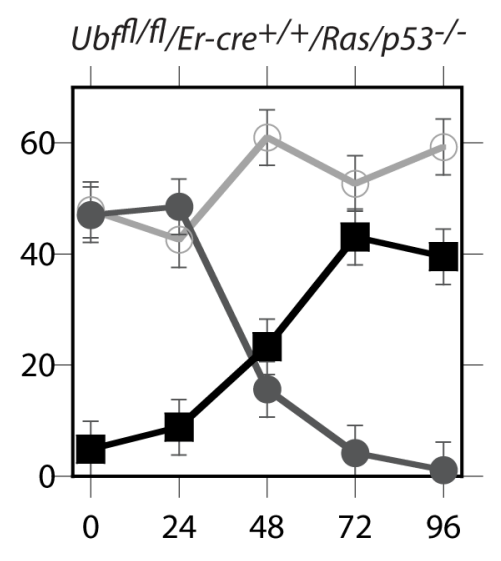

Hours post 4-HT

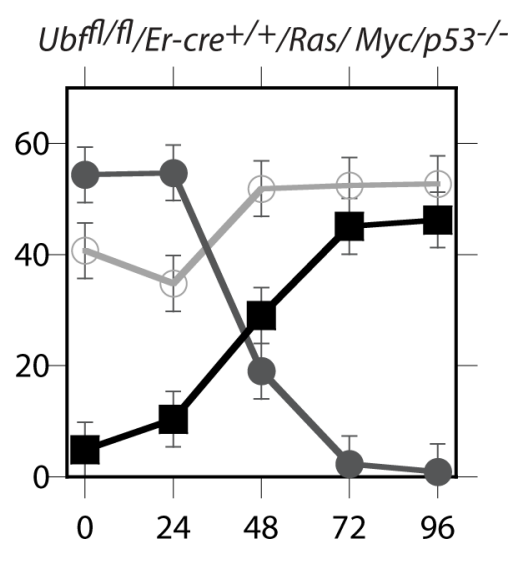

Hours post 4-HT

Figure 8: Cell cycle distribution of p53-null cells during UBF depletion. A. Untransformed $U b f^{t / f} / E r-c r e^{+/+} / p 53^{-/-}$and $U f^{v t / w t} / E r-c r e^{+/+} / p 53^{-/-}$MEFs. B. The same p53-null MEFs after transformation with SV40Tt, Ras or Ras plus Myc oncogenes. The graphics show the cell cycle distributions obtained from FACS analyses for active DNA replication (Click-iT ${ }^{\circledR}$ EdU) and G1 and G2 DNA content (propidium iodide, PI).

Recent studies of small molecule inhibitors that target ribosome biogenesis have further shown this may be a very valid clinical approach to treating a range of cancers [55, $56,76,77]$. However, while cell death was independent of p53 in the case of the GC-rich DNA interacting drug BMH-21 [56], it was found to be dependent on a functional p53 in the case of CX-5461, which is believed to target the pre-initiation complex factor SL1 [55]. Our data showing TIF1A/Rrn3-loss does not induce apoptosis even in the presence of p53 clearly excludes the explanation that the cytotoxicity of these drugs is simply a function of their ability to suppress rRNA synthesis. Why then inhibition of UBF can induce apoptotic cell death with such penetrance and in the complete absence of p53 is for the still a matter of conjecture. However, it is amost certainly related to the role of UBF in forming a specialized chromatin structure on the active rRNA genes [11]. Loss of this structure would yield the rRNA gene arrays highly susceptible to 
damage, and given the GC-richness of the rRNA genes the same could be argued for both cisplatin and BMH-21 drugs.

The Nucleolar Organizer Regions (NORs) each encompass around 40 rRNA gene units on the short arms of the five human acrocentric chromosomes [78]. These loci are particularly susceptible to DNA breakage and are subject to high levels of inter- and intra-chromosomal recombination [79-81]. Indeed, Robertsonian translocations have long been known to predominantly involve exchanges between the short arms of human acrocentric chromatids that often create fusions with chromatids of a metacentric chromosome [82]. Recent data strongly suggests that these and similar chromosome translocations result from disruption of the active chromatin structure of the rRNA genes, which in turn affects chromosome pairing causing aberrant resolution of mitotic chiasmata and fusion between nonhomologous chromatids [83]. Loss of UBF clearly disrupts the chromatin structure of the rRNA genes, leaving them at least transiently as naked DNA, and would necessarily leave these genes highly susceptible to DNA damage and breakage. Since transformed iMEFs continue replication during UBF depletion, the disruption of rRNA gene chromatin would exacerbate the effects of DNA breakage, probably inhibit homologous repair processes and hence destabilize the genome. Indeed such destabilization has recently been observed as a result of siRNA knockdown of UBF [84].

\section{MATERIALS AND METHODS}

\section{Isolation and cultures of MEFs and iMEFs}

The generation of conditional Ubf $f^{f l f l} \mathrm{Er}-\mathrm{cre}^{+/+}$ and control mouse lines was previously described [11]. The p53-null allele was introduced by crossing to strain 129-Trp53 $3^{\text {tmlTyj }} / J$ (Jackson Laboratory Stock \# 002080). Primary mouse embryonic fibroblasts (MEFs) from E14.5 Ubf fllfl/Er-cre $e^{+/+}$and isogenetic $U b f^{\text {wt } / w t} E r-c r e^{+/+}$ MEFs and corresponding $p 53^{--}$MEFs were prepared as previously described $[11,85]$. Cells were cultured in Dulbecco's modified Eagle medium (DMEM)-high glucose (Life Technologies), supplemented with 10\% fetal bovine serum (Wisent) and Antibiotic/Antimycotic (Wisent). Where indicated, Cisplatin (Sandoz) was added to the cell culture medium from a $100 \mathrm{mM}$ solution in DMSO to give a final concentration of $30 \mu \mathrm{M}$ and cells incubated for $4 \mathrm{hr}$ at $37^{\circ} \mathrm{C}$. The culture medium was then replaced with medium without cisplatin and cells incubated for a further $16 \mathrm{~h}$ at $37^{\circ} \mathrm{C}$, before processing for immunofluorescence as described below. MEFs were immortalized by the introduction of the SV40 Tt antigens by transfection with the pBSV0.3T/t, a modification of the pBSV-early vector [86] kindly provided by E. W.
Khandjian. The Ras and Ras/Myc transformed MEFs were generated by transfection or co-transfection with the plasmids pWZL-Ras-hygro and pBabe-c-myc-puro (kind gifts from Gerardo Ferbeyre) into Ubfflfl/ $E r-c r e^{+/+} / p 53^{-/-}$ MEFs and subsequent hygromycin or double hygromycin/ puromycin selection.

\section{Inactivation of $\boldsymbol{U b f}$ or Tifla in cell culture, and analysis of genotype, RNA and proteins}

As previously described [11], cells were initially plated in $6 \mathrm{~cm}$ petri dishes $\left(0.8 \times 10^{6}\right.$ cells each $)$ and cultured for 18 hours in DMEM, high glucose, $10 \%$ fetal bovine serum. To activate ER-Cre, 4-hydroxytamoxifen (4-HT) was added to a final concentration of $50 \mathrm{nM}$, and after $4 \mathrm{hr}$ incubation the medium replaced with fresh medium without 4-HT and cells harvested for analysis at various time points. In the case of Tifla, cells were treated with $50 \mathrm{nM} 4-\mathrm{HT}, 0 \mathrm{~h}$, then this treatment was repeated at $9 \mathrm{~h}, 24 \mathrm{~h}$ and $33 \mathrm{~h}$ later to ensure complete gene excision. Analyses of RNA, protein and genotype were systematically carried out on parallel cell cultures. Cells were genotyped by PCR before and after 4-HT treatment using the primers: A; 5'TGATCCCTCCCTTTCTGATG, B; 5'TGGGGATAGGCCTTAGAGAGA, C; 5'CACGGGAAAACAAGGTCACT, (Figure S2B). Metabolic labelling of RNA was carried out just before cell harvesting by addition of $10 \mu \mathrm{Ci}\left[{ }^{3} \mathrm{H}\right]$-uridine (PerkinElmer) to the culture medium and incubation for a further $3 \mathrm{~h}$. RNA was extracted with Trizol (Life Technologies) according to the manufacturer's protocol and analyzed by gel electrophoresis, fluoroimaging (ENHance, PerkinElmer) and RNA species quantitated by scintillation counting as previously described $[39,40]$. For total protein, cells were washed with cold PBS, scraped into PBS, centrifuged $30 \mathrm{~s}$ at 14000 r.p.m., then resuspended in sodium dodecyl sulphate (SDS) loading buffer. After fractionation on $8 \%, 12 \%$ or $5-15 \%$ gradient SDS-polyacrylamide gel electrophoresis (SDS-PAGE [87]), cell extracts were analysed by standard Western blotting procedures.

\section{Chromatin immunoprecipitations (ChIP)}

ChIP was performed as previously described $[11,88]$. The amplicon coordinates relative to the $47 \mathrm{~S}$ rRNA initiation site (BK000964) were as follows: 47SPr, 45133-40; ETS, 3078-3221; ITS1, 6258-6432; 28S, 10215-10411; T1-3, 13412-13607.

\section{Antibodies for western blot, immunofluorescence and ChIP}

Rabbit antibodies against UBF, RPI large subunit (A194), TTF-1 and TIF1A were generated 
in the laboratory. All other antibodies were obtained commercially; Anti-Caspase-3, -p53 and -H3S-28phospho (Cell Signalling), anti-Tubulin (Sigma) and anti-Fibrillarin (Covance).

\section{Immunofluorescence}

Cells were washed with PBS, fixed in 4\% paraformaldehyde /PBS for 15 minutes and permeabilized with $0.5 \%$ Triton/PBS for 5 minutes. Incubation with primary antibody was performed for $1 \mathrm{~h}$ in PBS-5\% BSA or $5 \%$ goat serum and cells were stained with AlexaFluor 488/568 conjugated anti-rabbit or -mouse IgG (Molecular Probes) and counterstained with DAPI. After mounting in $50 \%$ glycerol $/ 50 \% 0.2 \mathrm{M} \mathrm{Na-glycine,} 0.3 \mathrm{M} \mathrm{NaCl}$, $3 \mathrm{D}$ epifluorescent image stacks were generated on a Leica DMI6000B microscope equipped with a $63 \mathrm{x}$ or 100x objective and an Orca C4742-80-12AG camera (Hamamatsu). Image stacks were then deconvoluted and analyzed using Volocity software (Perkin-Elmer Improvision). Alternatively, image stacks were generated on a Leica SP5-II confocal microscope equipped with a $63 x$ objective and running in standard scanning mode, and analyzed using Volocity software (Perkin-Elmer Improvision).

\section{FACs analysis and determination of Mitotic Index}

Cells were stained for ongoing DNA synthesis using the Click-iT ${ }^{\circledR}$ EdU Alexa Fluor $^{\circledR} 647$ Flow Cytometry Assay Kit (Life Technologies) following the manufacturer's protocol and subsequently with propidium iodide (PI) immediately before analysis by the cytometry service of the CHU de Québec Research Centre using a FACSCanto II flow cytometer and FACSDiva 6.1.2 software (Becton Dickinson). Parallel cultures were stained with anti-H3S-28phospho antibody and DAPI and imaged by epifluorescence on the Leica DMI6000B microscope using 20 and 40x objectives. The Mitotic Index was calculated as the ratio of H3S-28phosphopositive to DAPI positive nuclei.

\section{Tunnel assays}

Tunnel assays were performed with a Click-It Tunnel assay kit, Alexa 488 Imaging System, (Life Technologies). Cells were seeded in $35 \mathrm{mM}$ petri dishes, fixed and processed according to the manufacturer's protocol and visualized by epifluorescence on the Leica DMI6000 B microscope using a 20x objective.

\section{Colony formation assays}

The SV40-T, Ras and Ras/Myc transformed Ubfflfl/ $\mathrm{Er}_{-} \mathrm{cre} \mathrm{H}^{+/} / \mathrm{p} 53^{-/-}$and the isogenic wild-type MEF cells cultured in $100 \mathrm{~mm}$ petri dishes were treated with $50 \mathrm{nM}$
4-HT (Sigma) on day 0. The medium was changed after four hours to remove 4-HT, and on day 2 each culture was replated in duplicate at dilutions of 10000,50000 , 100000 , and 200000 cells per $60 \mathrm{~mm}$ petri. On day 6 and day 12 petri dishes were fixed for 5 mins with $4 \%$ paraformaldehyde/PBS and stained with $0.05 \%$ crystal violet in distilled water (filtered) for 30 mins. Petri dishes were then washed 3 times with water and left inverted to dry before being photographed.

\section{MitoTracker assays}

Cells were plated in Ibidi $35 \mathrm{~mm}$ thin bottom petri dishes for subsequent live cell microscopy and treated for $4 \mathrm{~h}$ with $50 \mathrm{nM}$ 4-HT (Sigma) and further cultured as standard for $96 \mathrm{~h}$ to induce UBF loss. Cells were then treated with $25 \mathrm{nM}$ MitoTracker DeepRedTM (Life Technologies) for $20 \mathrm{mins}$ at $37^{\circ} \mathrm{C}$ in DMEM minus serum. Petri dishes were washed once with DMEM minus serum and then incubated in FluoroBrite DMEM (Life Technologies). Finally, live image stacks were generated on the Leica SP5-II confocal microscope and analyzed using Volocity software (Perkin-Elmer Improvision).

\section{ACKNOWLEDGMENTS}

We wish to thank Dr Lucie Jeannotte for providing the p53 null allele mice and advice on their use, Dr Ross Hannan and Elaine Sanij for discussion at various stages of this work, and Dr A. Brunet of the Cytology Laboratory of the Research Centre of the Québec University Hospital Centre (RC-CHUQ) for FACS analyses. This work was funded by operating grants from the Canadian Institutes of Health Research (CIHR, MOP12205) and from the Cancer Research Society (CRS/SRC). The Research Centre of the Québec University Hospital Centre (CHU de Québec) is supported by the Fonds de recherche du Québec - Santé (FRQS).

\section{CONFLICTS OF INTEREST}

\section{None.}

\section{REFERENCES}

1. Rabik CA, Dolan ME. Molecular mechanisms of resistance and toxicity associated with platinating agents. Cancer Treat Rev. 2007; 33:9-23.

2. Wang Z, Xu J, Zhou JY, Liu Y, Wu GS. Mitogen-activated protein kinase phosphatase-1 is required for cisplatin resistance. Cancer Res. 2006; 66:8870-8877.

3. Kim M, Yan Y, Kortum RL, Stoeger SM, Sgagias MK, Lee $\mathrm{K}$, Lewis RE, Cowan KH. Expression of kinase 
suppressor of Ras1 enhances cisplatin-induced extracellular signal-regulated kinase activation and cisplatin sensitivity. Cancer Res. 2005; 65:3986-3992.

4. Cavallo F, Feldman DR, Barchi M. Revisiting DNA damage repair, p53-mediated apoptosis and cisplatin sensitivity in germ cell tumors. Int J Dev Biol. 2013; 57:273-280.

5. Jacobsen C, Honecker F. Cisplatin resistance in germ cell tumours: models and mechanisms. Andrology. 2014; .

6. Boulikas T. DNA lesion-recognizing proteins and the p53 connection. Anticancer Res. 1996; 16:225-242.

7. Wozniak K, Blasiak J. Recognition and repair of DNAcisplatin adducts. Acta Biochim Pol. 2002; 49:583-596.

8. Reeves R, Adair JE. Role of high mobility group (HMG) chromatin proteins in DNA repair. DNA Repair (Amst). 2005; 4:926-938.

9. Pil PM, Lippard SJ. Specific binding of chromosomal protein HMG1 to DNA damaged by the anticancer drug cisplatin. Science. 1992; 256:234-237.

10. Hoffmann JS, Locker D, Viliani G, Leng M. HMG1 protein inhibits the translesion synthesis of the major DNA cisplatin adduct by cell extracts. JMolBiol. 1997; 270:539-543.

11. Hamdane N, Stefanovsky VY, Tremblay MG, Nemeth A, Paquet E, Lessard F, Sanij E, Hannan R, Moss T. Conditional inactivation of Upstream Binding Factor reveals its epigenetic functions and the existence of a somatic nucleolar precursor body. PLoS Genet. 2014; 10:e1004505.

12. Merz K, Hondele M, Goetze H, Gmelch K, Stoeckl U, Griesenbeck J. Actively transcribed rRNA genes in S. cerevisiae are organized in a specialized chromatin associated with the high-mobility group protein $\mathrm{Hmol}$ and are largely devoid of histone molecules. Genes Dev. 2008; 22:1190-1204.

13. Gagnon-Kugler T, Langlois F, Stefanovsky V, Lessard F, Moss T. Loss of human ribosomal gene $\mathrm{CpG}$ methylation enhances cryptic RNA polymerase II transcription and disrupts ribosomal RNA processing. Mol Cell. 2009; 35:414-425.

14. Chao JC, Wan XS, Engelsberg BN, Rothblum LI, Billings PC. Intracellular distribution of HMG1, HMG2 and UBF change following treatment with cisplatin. Biochim Biophys Acta. 1996; 1307:213-219.

15. Delmani FA, Torreblanca J, Moreno J, Garcia-Herdugo G, Vilaplana R, Gonzalez-Viltchez F. In vitro expression and redistribution of nucleolar proteins following the treatment with cis-dichloro-1, 2-propylenediamine-N, N, N', N'-tetraacetato ruthenium (III) (RAP). Oncology research. 2009; 17:425-435.

16. Zhai XQ, Beckmann H, Jantzen HM, Essigmann JM. Cisplatin-DNA adducts inhibit ribosomal RNA synthesis by hijacking the transcription factor human upstream binding factor. Biochemistry. 1998; 37:16307-16315.
17. Jordan P, Carmo-Fonseca M. Cisplatin inhibits synthesis of ribosomal RNA in vivo. Nucleic Acids Res. 1998; 26:2831-2836.

18. Codony-Servat J, Gimeno R, Gelpi C, RodriguezSanchez JL, Juarez C. The two isoforms of the $90-\mathrm{kDalton}$ nucleolus organizer region autoantigen (upstream binding factor) bind with different avidity to DNA modified by the antitumor drug cisplatin. Biochemical Pharmacology. 1996; 51:1131-1136.

19. Treiber DK, Zhai X, Jantzen HM, Essigmann JM. CisplatinDNA adducts are molecular decoys for the ribosomal RNA transcription factor hUBF (human upstream binding factor). ProcNatlAcadSciUSA. 1994; 91:5672-5676.

20. Grummt I. Life on a planet of its own: regulation of RNA polymerase I transcription in the nucleolus. Genes Dev. 2003; 17:1691-1702.

21. Moss T, Langlois F, Gagnon-Kugler T, Stefanovsky V. A housekeeper with power of attorney: the rRNA genes in ribosome biogenesis. Cell Mol Life Sci. 2007; 64:29-49.

22. Russell J, Zomerdijk JC. RNA-polymerase-I-directed rDNA transcription, life and works. Trends Biochem Sci. 2005; 30:87-96.

23. Sanij E, Poortinga G, Sharkey K, Hung S, Holloway TP, Quin J, Robb E, Wong LH, Thomas WG, Stefanovsky V, Moss T, Rothblum L, Hannan KM, McArthur GA, Pearson RB, Hannan RD. UBF levels determine the number of active ribosomal RNA genes in mammals. J Cell Biol. 2008; 183:1259-1274.

24. Bazett-Jones DP, Leblanc B, Herfort M, Moss $\mathrm{T}$. Short-range DNA looping by the Xenopus HMG-box transcription factor, xUBF. Science. 1994; 264:1134-1137.

25. Stefanovsky VY, Pelletier G, Bazett-Jones DP, CraneRobinson C, Moss T. DNA looping in the RNA polymerase I enhancesome is the result of non-cooperative in-phase bending by two UBF molecules. Nucleic Acids Res. 2001; 29:3241-3247.

26. Stefanovsky VY, Moss T. The splice variants of UBF differentially regulate RNA polymerase I transcription elongation in response to ERK phosphorylation. Nucleic Acids Res. 2008; 36:5093-5101.

27. Stefanovsky VY, Langlois F, Pelletier G, Bazett-Jones DP, Moss T. ERK modulates DNA bending and Enhancesome Structure by phosphorylating HMG1-boxes 1 and 2 of the RNA polymerase I transcription factor UBF. Biochemistry. 2006; 45:3626-3634.

28. O'Sullivan AC, Sullivan GJ, McStay B. UBF binding in vivo is not restricted to regulatory sequences within the vertebrate ribosomal DNA repeat. Mol Cell Biol. 2002; 22:657-668.

29. Woolford JL Jr, Baserga SJ. Ribosome biogenesis in the yeast Saccharomyces cerevisiae. Genetics. 2013; 195:643-681. 
30. Derenzini M, Trerè D, Pession A, Montanaro L, Sirri V, Ochs RL. Nucleolar function and size in cancer cells. AmJPathol. 1998; 152:1291-1297.

31. Montanaro L, Trere D, Derenzini M. Nucleolus, ribosomes, and cancer. Am J Pathol. 2008; 173:301-310.

32. Derenzini M, Montanaro L, Trere D. What the nucleolus says to a tumour pathologist. Histopathology. 2009; 54:753-762.

33. Guttman PH, Halpern S. Nuclear-Nucleolar Volume Ratio in Cancer. The American Journal of Cancer. 1935; 25:802-806.

34. Derenzini M, Trerè D, Pession A, Govoni M, Sirri V, Chieco P. Nucleolar size indicates the rapidity of cell proliferation in cancer tissues. J Pathol. 2000; 191:181-186.

35. Poortinga G, Hannan KM, Snelling H, Walkley CR, Jenkins A, Sharkey K, Wall M, Brandenburger Y, Palatsides M, Pearson RB, McArthur GA, Hannan RD. MAD1 and c-MYC regulate UBF and rDNA transcription during granulocyte differentiation. Embo J. 2004; 23:3325-3335.

36. Arabi A, Wu S, Ridderstrale K, Bierhoff H, Shiue C, Fatyol K, Fahlen S, Hydbring P, Soderberg O, Grummt I, Larsson L-G, Wright APH. c-Myc associates with ribosomal DNA and activates RNA polymerase I transcription. Nat Cell Biol. 2005; 7:303-310.

37. Zhai WG, Tuan JA, Comai L. SV40 large T antigen binds to the TBP-TAFI complex SL1 and coactivates ribosomal RNA transcription. GenesDev. 1997; 11:1605-1617.

38. Tuan JC, Zhai WG, Comai L. Recruitment of TATAbinding protein-TAF, complex SL1 to the human ribosomal DNA promoter is mediated by the carboxy-terminal activation domain of upstream binding factor (UBF) and is regulated by UBF phosphorylation. MolCell Biol. 1999; 19:2872-2879.

39. Stefanovsky V, Langlois F, Gagnon-Kugler T, Rothblum LI, Moss T. Growth factor signaling regulates elongation of RNA polymerase I transcription in mammals via UBF phosphorylation and r-chromatin remodeling. Mol Cell. 2006; 21:629-639.

40. Stefanovsky VY, Pelletier G, Hannan R, Gagnon-Kugler T, Rothblum LI, Moss T. An immediate response of ribosomal transcription to growth factor stimulation in mammals is mediated by ERK phosphorylation of UBF. Mol Cell. 2001; 8:1063-1073.

41. Zhao J, Yuan X, Frodin M, Grummt I. ERK-Dependent Phosphorylation of the Transcription Initiation Factor TIF-IA Is Required for RNA Polymerase I Transcription and Cell Growth. Mol Cell. 2003; 11:405-413.

42. Mayer C, Zhao J, Yuan X, Grummt I. mTOR-dependent activation of the transcription factor TIF-IA links rRNA synthesis to nutrient availability. Genes Dev. 2004; 18:423-434.

43. Hannan KM, Brandenburger Y, Jenkins A, Sharkey K, Cavanaugh A, Rothblum L, Moss T, Poortinga G,
McArthur GA, Pearson RB, Hannan RD. mTOR-dependent regulation of ribosomal gene transcription requires $\mathrm{S} 6 \mathrm{~K} 1$ and is mediated by phosphorylation of the carboxy-terminal activation domain of the nucleolar transcription factor UBF. Mol Cell Biol. 2003; 23:8862-8877.

44. Zhai W, Comai L. Repression of RNA polymerase I transcription by the tumor suppressor p53. Mol Cell Biol. 2000; 20:5930-5938.

45. Zhang Y, Saporita AJ, Weber JD. P19ARF and RasV(1)(2) offer opposing regulation of DHX33 translation to dictate tumor cell fate. Mol Cell Biol. 2013; 33:1594-1607.

46. Lessard F, Morin F, Ivanchuk S, Langlois F, Stefanovsky V, Rutka J, Moss T. The ARF tumor suppressor controls ribosome biogenesis by regulating the RNA polymerase I transcription factor TTF-I. Mol Cell. 2010; 38:539-550.

47. Sugimoto M, Kuo ML, Roussel MF, Sherr CJ. Nucleolar Arf tumor suppressor inhibits ribosomal RNA processing. Mol Cell. 2003; 11:415-424.

48. Cavanaugh AH, Hempel WM, Taylor LJ, Rogalsky V, Todorov G, Rothblum LI. Activity of RNA polymerase I transcription factor UBF blocked by $\mathrm{Rb}$ gene product. Nature. 1995; 374:177-180.

49. Pelletier G, Stefanovsky VY, Faubladier M, HirschlerLaszkiewicz I, Savard J, Rothblum LI, Cote J, Moss T. Competitive recruitment of $\mathrm{CBP}$ and $\mathrm{Rb}-\mathrm{HDAC}$ regulates UBF acetylation and ribosomal transcription. Mol Cell. 2000; 6:1059-1066.

50. Zhang C, Comai L, Johnson DL. PTEN represses RNA Polymerase I transcription by disrupting the SL1 complex. Mol Cell Biol. 2005; 25:6899-6911.

51. Bursac S, Brdovcak MC, Donati G, Volarevic S. Activation of the tumor suppressor p53 upon impairment of ribosome biogenesis. Biochim Biophys Acta. 2014; 1842:817-830.

52. Rubbi CP, Milner J. Disruption of the nucleolus mediates stabilization of p53 in response to DNA damage and other stresses. Embo J. 2003; 22:6068-6077.

53. Pestov DG, Strezoska Z, Lau LF. Evidence of p53dependent cross-talk between ribosome biogenesis and the cell cycle: effects of nucleolar protein Bop1 on G(1)/S transition. Mol Cell Biol. 2001; 21:4246-4255.

54. Fumagalli S, Di Cara A, Neb-Gulati A, Natt F, Schwemberger S, Hall J, Babcock GF, Bernardi R, Pandolfi PP, Thomas G. Absence of nucleolar disruption after impairment of $40 \mathrm{~S}$ ribosome biogenesis reveals an rpL11-translation-dependent mechanism of p53 induction. Nat Cell Biol. 2009; 11:501-508.

55. Bywater MJ, Poortinga G, Sanij E, Hein N, Peck A, Cullinane C, Wall M, Cluse L, Drygin D, Anderes K, Huser N, Proffitt C, Bliesath J, Haddach M, Schwaebe MK, Ryckman DM, et al. Inhibition of RNA Polymerase I as a Therapeutic Strategy to Promote Cancer-Specific Activation of p53. Cancer Cell. 2012; 22:51-65.

56. Peltonen K, Colis L, Liu H, Trivedi R, Moubarek MS, Moore HM, Bai B, Rudek MA, Bieberich CJ, Laiho M. A 
Targeting Modality for Destruction of RNA Polymerase I that Possesses Anticancer Activity. Cancer Cell. 2014; 25:77-90.

57. Duenas-Gonzalez A, Cetina L, Coronel J, Cervantes-Madrid D. Emerging drugs for cervical cancer. Expert opinion on emerging drugs. 2012; 17:203-218.

58. Ho KF, Swindell R, Brammer CV. Dose intensity comparison between weekly and 3-weekly Cisplatin delivered concurrently with radical radiotherapy for head and neck cancer: a retrospective comparison from New Cross Hospital, Wolverhampton, UK. Acta Oncol. 2008; 47:1513-1518.

59. Mietz JA, Unger T, Huibregtse JM, Howley PM. The transcriptional transactivation function of wild-type p53 is inhibited by SV40 large T-antigen and by HPV-16 E6 oncoprotein. Embo J. 1992; 11:5013-5020.

60. Lin JY, Simmons DT. The ability of large T antigen to complex with p53 is necessary for the increased life span and partial transformation of human cells by simian virus 40 . J Virol. 1991; 65:6447-6453.

61. Duke RC, Chervenak R, Cohen JJ. Endogenous endonuclease-induced DNA fragmentation: an early event in cell-mediated cytolysis. Proc Natl Acad Sci U S A. 1983; 80:6361-6365.

62. Wyllie AH. Glucocorticoid-induced thymocyte apoptosis is associated with endogenous endonuclease activation. Nature. 1980; 284:555-556.

63. Cote J, Ruiz-Carrillo A. Primers for mitochondrial DNA replication generated by endonuclease G. Science. 1993; 261:765-769.

64. Li LY, Luo X, Wang X. Endonuclease G is an apoptotic DNase when released from mitochondria. Nature. 2001; 412:95-99.

65. Lowe SW, Bodis S, McClatchey A, Remington L, Ruley HE, Fisher DE, Housman DE, Jacks T. p53 status and the efficacy of cancer therapy in vivo. Science. 1994; 266:807-810.

66. Lowe SW, Ruley HE, Jacks T, Housman DE. p53-dependent apoptosis modulates the cytotoxicity of anticancer agents. Cell. 1993; 74:957-967.

67. Weller M. Predicting response to cancer chemotherapy: the role of p53. Cell Tissue Res. 1998; 292:435-445.

68. Markert EK, Levine AJ, Vazquez A. Proliferation and tissue remodeling in cancer: the hallmarks revisited. Cell death \& disease. 2012; 3:e397.

69. Gibbons JJ, Abraham RT, Yu K. Mammalian target of rapamycin: discovery of rapamycin reveals a signaling pathway important for normal and cancer cell growth. Semin Oncol. 2009; 36:S3-S17.

70. Datta J, Ghoshal K, Denny WA, Gamage SA, Brooke DG, Phiasivongsa P, Redkar S, Jacob ST. A new class of quinoline-based DNA hypomethylating agents reactivates tumor suppressor genes by blocking DNA methyltransferase
1 activity and inducing its degradation. Cancer Res. 2009; 69:4277-4285.

71. Flotho C, Claus R, Batz C, Schneider M, Sandrock I, Ihde S, Plass C, Niemeyer CM, Lubbert M. The DNA methyltransferase inhibitors azacitidine, decitabine and zebularine exert differential effects on cancer gene expression in acute myeloid leukemia cells. Leukemia. 2009; 23:1019-1028.

72. Tsai HC, Li H, Van Neste L, Cai Y, Robert C, Rassool FV, Shin JJ, Harbom KM, Beaty R, Pappou E, Harris J, Yen RW, Ahuja N, Brock MV, Stearns V, Feller-Kopman D, et al. Transient low doses of DNAdemethylating agents exert durable antitumor effects on hematological and epithelial tumor cells. Cancer Cell. 2012; 21:430-446.

73. Cihak A, Weiss JW, Pitot HC. Characterization of polyribosomes and maturation of ribosomal RNA in hepatoma cells treated with 5-azacytidine. Cancer Res. 1974; 34:3003-3009.

74. Cihak A. Biological effects of 5-azacytidine in eukaryotes. Oncology. 1974; 30:405-422.

75. Moss T. DNA methyltransferase inhibition may limit cancer cell growth by disrupting ribosome biogenesis. Epigenetics. 2011; 6:128-133.

76. Drygin D, Lin A, Bliesath J, Ho CB, O'Brien SE, Proffitt C, Omori M, Haddach M, Schwaebe MK, Siddiqui-Jain A, Streiner N, Quin JE, Sanij E, Bywater MJ, Hannan RD, Ryckman D, et al. Targeting RNA Polymerase I with an Oral Small Molecule CX-5461 Inhibits Ribosomal RNA Synthesis and Solid Tumor Growth. Cancer Res. 2011; 71:1418-1430.

77. Rothblum K, Hu Q, Penrod Y, Rothblum LI. Selective inhibition of rDNA transcription by a small-molecule peptide that targets the interface between RNA polymerase I and Rrn3. Mol Cancer Res. 2014; 12:1586-1596.

78. McStay B, Grummt I. The epigenetics of rRNA genes: from molecular to chromosome biology. Annu Rev Cell Dev Biol. 2008; 24:131-157.

79. Tchurikov NA, Fedoseeva DM, Sosin DV, Snezhkina AV, Melnikova NV, Kudryavtseva AV, Kravatsky YV, Kretova OV. Hot spots of DNA double-strand breaks and genomic contacts of human rDNA units are involved in epigenetic regulation. J Mol Cell Biol. 2014; .

80. Postepska-Igielska A, Krunic D, Schmitt N, Greulich-Bode KM, Boukamp P, Grummt I. The chromatin remodelling complex NoRC safeguards genome stability by heterochromatin formation at telomeres and centromeres. EMBO Rep. 2013; 14:704-710.

81. Ide S, Miyazaki T, Maki H, Kobayashi T. Abundance of ribosomal RNA gene copies maintains genome integrity. Science. 2010; 327:693-696.

82. Therman E, Susman B, Denniston C. The nonrandom participation of human acrocentric chromosomes in 
Robertsonian translocations. Annals of human genetics. 1989; 53:49-65.

83. Stimpson KM, Sullivan LL, Kuo ME, Sullivan BA. Nucleolar organization, ribosomal DNA array stability, and acrocentric chromosome integrity are linked to telomere function. PLoS One. 2014; 9:e92432.

84. Sanij E, Diesch J, Lesmana A, Poortinga G, Lidgerwood G, Hein N, Cameron DP, Ellul J, Goodall GJ, Wong LH, Dhillon AS, Hamdane N, Rothblum LI, Pearson RB, Haviv I, Moss T, et al. A novel role for the Pol I transcription factor UBTF in maintaining genome stability through the regulation of highly transcribed Pol II genes. Genome Res. 2014.

85. Giroux S, Tremblay M, Bernard D, Cadrin-Girard JF, Aubry S, Larouche L, Rousseau S, Huot J, Landry J, Jeannotte L, Charron J. Embryonic death of Mek1-deficient mice reveals a role for this kinase in angiogenesis in the labyrinthine region of the placenta. Curr Biol. 1999; 9:369-372.

86. Schaffner W. Direct transfer of cloned genes from bacteria to mammalian cells. Proceedings of the National Academy of Sciences of the United States of America. 1980; 77:2163-2167.

87. Laemmli UK. Cleavage of structural proteins during the assembly of the head of bacteriophage T4. Nature. 1970; 227:680-685.

88. Nelson JD, Denisenko O, Bomsztyk K. Protocol for the fast chromatin immunoprecipitation (ChIP) method. Nat Protoc. 2006; 1:179-185. 